\title{
A PROCESS CONTROL SENSOR \\ FOR THE GLASS INDUSTRY
}

Phase 1, Extended Development Program

August 1992

Work Performed Under Contract No. DE-FCO7-89ID12781

For

U. S. Department of Energy office of Industrial Technologies Washington, D.C.

By

Energy and Environmental Research Corporation Irvine, California 92718

\section{MASIER}

DISTRIBUTION OF THIS DOCUMENT IS UNLIMITED 


\title{
A PROCESS CONTROL SENSOR
}

\section{FOR THE GLASS INDUSTRY}

Phase I, Extended Development Program

August 1992

Work Performed Under Contract No. DE-FC07-891D12781

\author{
Prepared for the \\ U.S. Department of Energy \\ Under DOE Idaho Field office \\ Sponsored by the Office of the Assistant Secretary \\ for Conservation and Renewable Energy \\ office of Industrial Technologies \\ Washington, D.C. \\ Prepared by \\ Energy and Environmental Research Corporation \\ 18 Mason \\ Irvine, California 92718
}




\section{$\ldots \quad$ TABLE OF CONTENTS}

Section

Page

EXECUTIVE SUMMARY $\ldots \ldots \ldots \ldots \ldots \ldots \ldots \ldots \ldots \ldots \ldots \ldots \ldots \ldots \ldots$

1.0 INTRODUCTION AND BACKGROUND $\ldots \ldots \ldots \ldots \ldots \ldots \ldots \ldots \ldots$

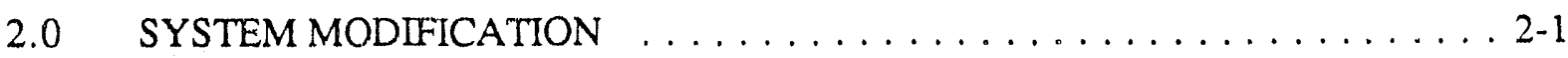

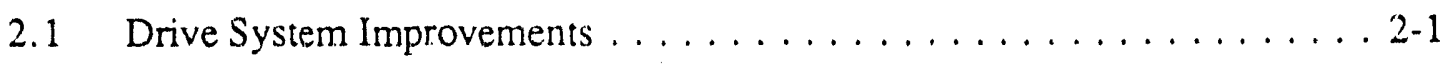

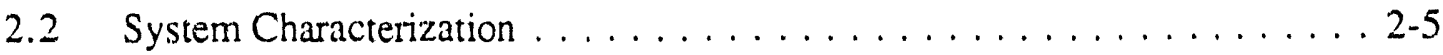

2.3 Enclosure Thermal Control . . . . . . . . . . . . . . . . . . . 2-9

3.0 SYSTEM CALIBRATION DEVELOPMENT $\ldots \ldots \ldots \ldots \ldots \ldots \ldots \ldots .3-1$

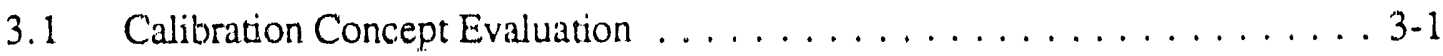

3.2 Element Testing $\ldots \ldots \ldots \ldots \ldots \ldots \ldots \ldots \ldots \ldots \ldots \ldots \ldots \ldots \ldots$

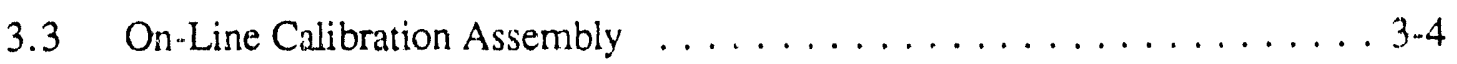

4.0 TAS PROCESS SIMULATION TESTING $\ldots \ldots \ldots \ldots \ldots \ldots \ldots \ldots .4 .1$

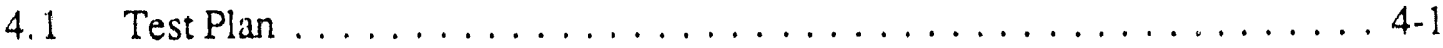

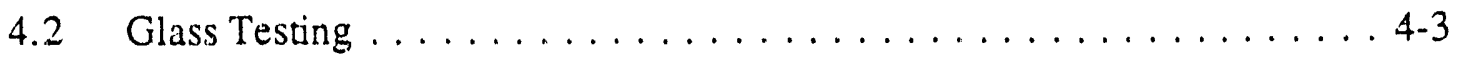

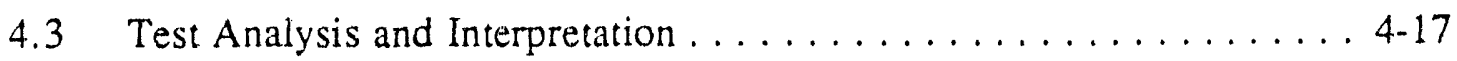

5.0 CONCLUSIONS AND RECOMMENDATIONS $\ldots \ldots \ldots \ldots \ldots \ldots \ldots .1$

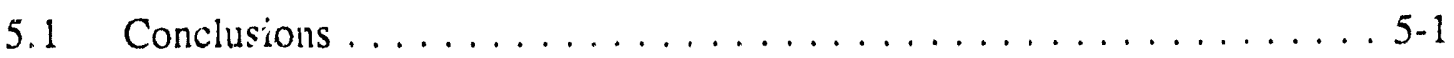

5.2 Recommendations ....................... 5-2

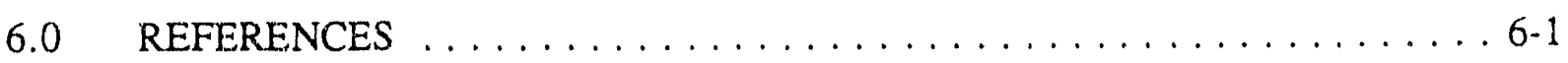




\section{EXECUTIVE SUMMARY}

Development work on a prototype sensor for mapping temperature gradients at depth in glass melts was continued under the first of a two phase development and field verification program. The current work was directed at resolving several design deficiencies identified ${ }_{1}$ in the earlier Phase which prohibited achieving the goal of $\pm 1^{\circ} \mathrm{C}$ precision at a nominal melt operating temperature of $1100^{\circ} \mathrm{C}$. Accuracies approaching $\pm 3^{\circ} \mathrm{C}$ were achieved in that program and the concept of deconvoluting infrared emission signatures to temperature gradient was demonstrated with a remote sensing system.

\section{Modifications}

The following design modifications were made to correct the long term drift and short term noise identified with thermal and mechanical design deficiencies:

- The metal chain multiplexer drive was replaced with a precision timing belt .

- The signal processor NEMA 4 enclosure was actively temperature controlled to within $\pm 1 / 2^{\circ} \mathrm{C}$.

The rationale for and the results of these modifications are summarized below in Section 2 .

\section{Gradient Measurements}

The extended phase proof of principle testing in the pilot scale furnace has shown satisfactory correlation between iriplex and sensor surface temperature measurements, Section 4. Unfortunately, resolution at depth has been difficult. An investigation as to cause centered around the fact that all glass melts used in the current test have visually significant bubbles and seeds. The optical effect can be considerable since the bubbles significantly distort the optical path, resulting in signal scattering and losses due to:

- Mei scattering from bubbles with diameters greater than the measurement optical wavelength, i.e.: Refraction and reflection at the gas bubble-melt interface. 
The significantly higher bubble content relative to earlier pilot testing is primarily due to a deteriorated furnace and a conscious decision to run at lower melt temperatures, $1800-2000^{\circ} \mathrm{F}$ $\left(980-1100^{\circ} \mathrm{C}\right)$ and shorter residence times (days instead of weeks) which provided significantly less degassing. It should be appreciated that glass refiners in comm reial plants are typically operated at $2600^{\circ} \mathrm{F}\left(1425^{\circ} \mathrm{C}\right)$.

\section{Bench Scale Stability Evaluation}

A number of potential causes for the short and long term analyzer drift were postulated and both coarse and precision experiments were conducted to assess design sensitivities to the environment and the effectiveness of various modifications. Initial calibrations and long term observations with a precision $\left( \pm 0.4^{\circ} \mathrm{C}\right)$ black body source suggested some correlation between drift and cycling (diurnal) ambient temperatures. Coarse cold shock tests on potentially temperature sensitive optics suggested that subtle gradients were causing micro misalignments of the optical path. Active temperature control of the spectrometer enclosure and replacement of the metal chain drive with a precision timing belt substantially improved long term drift and improved short term. accuracy to approximately $\pm 1 / 2^{\circ} \mathrm{C}$. Substitution of the high thermal expansion aluminum opticaf bench frame with a low thermal expansion material should substantially eliminate the diurnal drift problem.

\section{In-Situ Black Body Calibration}

An altemative approach to dealing with long term drift is to provide frequent, automatic in situ calibrations of the sensor. Since drift may be caused by any component deterioration along the optical path (sensor minor to photo detector) placement of the calibration source within the sensor sight tube was deemed desirable. A number of broad band infrared illumination source designs were conceptualized including:

- Electrically heated ceramic strips and wires (with and without a reference temperature sensor).

- $\quad$ Process heated targets with temperature sensors.

Several ceramic strip heaters commonly used for gas appliance pilotless ignition were selected for initial evaluation because they are relatively inexpensive (\$10/Unit) in production quantities, have good black body emission characteristics, and good reliability through repeated 
temperature cycles. The strip heater was placed on an axially translating solenoid driven actuator for insertion into the optical pach. The frequency of insertion and data acquisition can be under the control of the analyzer: CPU.

Initial testing of a long term cycling test was initiated to evaluate stability and repeatability. The best strip heater was initially stable, but after about 48 hours of operation started to show unacceptable variability. This approach clearly will require a significant development effort to perfect.

Rather than pursue this approach and based upon the good long term stability now being achieved with the modified prototype analyzer the following calibration approach was provisionally selected:

- Core a second hole (1"dia) next to an existing glass sensor.

- Periodically (field test to determine) insert a triplex thermocouple and initiate a sensor calibration mode (all automatic under analyzer control).

This approach returns the concept to a simple passive sensor design and a calibration relative to an industrial standard. Some additional instrument technician labor is incurred, but it should be modest if system stability is sufficient to require only monthly calibrations.

\section{Conclusions}

The detailed analysis and testing of the modified sensing system is summarized by the following conclusions.

1. Analyzer long term drift and short term noise improvements have resulted in inherent accuracies of about $\pm 1 / 2{ }^{\circ} \mathrm{C}$, about equivalent to the black body calibration sourrce-

2. Four different concepts of heating elements were evaluated for use in an in-situ secondary calibration source. The use of a SiN igniter element shows some promise, but requires considerable development. 
3. The black body reference is the source of some of the apparent diumal analyzer drift due to ambient termperature changes.

4. The anatyzer has strong ambient temperature sensitivities, specifically the detector and optical bench, which can be substantially mitigated with good internal temperature control (enclosure and detector).

5. Pilot furnace tests using poorly degassed glasses resulted in data which makes conclusions regarding the effects of glass composition and gradient resolution impossible.

6. The impact of bubble inclusions in the glass melt can yield a significant degradation in depth measurement capability as a result of Mei scattering from the bubbles. The degree of ciegradation depends on bubble size and number density.

The above conclusions indicate the program has made significant progress towards: correcting previously found deficiencies and has revealed the limitations of the pilot scale test= program. Improvements in glass homogeneity, ambient temperature compensation and calibration techniques will offer a high probability of achievement of the accuracy goals in the Phase II program.

\section{Planned Work}

With this background and experience behind us two approaches to continuing the project might be considered:

- Implement the Phase II, Industrial Testing and Verification, at Gallo initially with two sensors and the current prototype.

- Procure a thermally compatible crucible, melt and degas the glass in a contracted, high temperature furnace at $2600^{\circ} \mathrm{F}\left(1400^{\circ} \mathrm{C}\right)$, then use the preconditioned melt in the pilot furnace.

The preferred option is to initiate a two port field verification program; two sensor calibration and durability test followed by balance of system installation and furnace optimization. 
Sufficientadevelopment and proof of principle work has been completed to execute a two sensor installation at Gallo. Set up costs are projected to be relatively modest. The sensors would be placed adjacent to: an existing triplex thermocouple and the pilot scale experiment would be substantially duplicated. This approach avoids the complexity of attempting a process simulation and should provide a clear go-no go decision regarding the balance Phase II implementation. The combined analyzer data base of:

- The earlier pilot furnace experiments, methods evaluation and concept development.

- The black body stability tests with the newly improved sensor design.

- The current pilot furnace surface temperature data.

suggests this to be low risk, low cost approach producing an unambiguous result.

The proven hardware (modified as appropriate) and balance of system hardware/software will be installed and a baseline forehearth performance test initiated. The glass sensor system wilf then be used to optimize operations. 
This interim report describes Energy and Environmental Research Corporation's (EER) work under a Phase F, Development proposal to the U.S. Department of Energy in response to solicitation entitled "Development of Process Control Sensor for the Glass Industry." The results of an extended program to re:solve several critical design deficiencies is presented.

The current work was directed at completing several value engineering activities to improve the overall accuracy and precision of the analyzer and to demonstrate their effectiveness using a pilot scale furnace and actual glass melts. Specifically, design modifications were investigated leading to:

- The correction of short term signal noise and long term drift.

- In-situ calibration at each sensor head.

Modifications were implemented and evaluated with a precision black body reference source. The improved analyzer was then evaluated in a pilot scale furnace to confirm that the performance objectives were met on several typical container glass melts.

The work was performed in an extended Phase I, Task 4A program having the following sub tasks:

- System design improvements.

- In-sensor calibrator design.

- $\quad$ Selective pilot scale tests.

\section{System Design Imp̄roverments}

The design deficiencies affecting system noise and drift that were discovered during Phase I laboratory testing were diagnosed and corrected. Both mechanical, optical, and thermal effects were investigated. For example, the ladder chain and sprocket drive system that connects the motor to the rotating multiplexer stretched after a few hours of operation. The resulting slack creates a signal alignment problem which contributes to the system noise. A more durable belt 
drive system was evaluated as an alternative. The heat sinking effectiveness of the thermal electric cooler (TEC) used to cool the lead sulfide detector was also suspect. If the detector temperature is not maintained properly, its photon efficiency will cause signal changes that would appear as drift. The need to correct the thermal design at the contact surfaces and/or in providing more effective heat dissipation was also evaluated. The potential sensitivity of critical electro-optic and optic components to temperature was also investigated.

Modifications were sequentially made and the noise and drift characteristics of the Temperature Analyzer System were determined using a Black Body Reference Standard.

\section{In Sensor Calibrator Source}

The calibration source previously developed used a notched SiC block with an embedded therrnocouple. While this was functional it is not practical for field use. Several calibration source methods, integrated with the sensor head, were conceptualized and all concepts using a heated: ceramic element was designed, fabricated and evaluated at prototype.

\section{Modified Sensor Test and Evaluation}

The redesigned system components and improved firmware were evaluated in the pilot furnace under melt isothermal and temperature gradient test conditions. The results of both tests were compared and performance improvements verified. The effects of factors potentially affecting emissivity were also studied. Specifically, variations in contaminants such as iron or soda were characterized, which may change the emissivity of the glass.

The results of this work are described by major task in Sections 2.0 through 4.0 Recommendation for future work are described in Section 5.0. 
Several design deficiencies affecting system noise and drift were discovered during the laboratory testing (Task 4) during the original Phase I sensor development program ${ }_{1}$. The first problem identified and resolved was the drive system that connects the motor to the rotating part of the optical bench. The ladder chain and sprocket system is inexpensive but found to stretch after a few hours of operation. The resulting linkage slack created a signal alignment problem contributing to the system noise. This problem was addressed by researching and redesigning the optical bench with a more durable drive system. The second froblem was related to poor heat sinking of the thermal electric cooler used to cool the lead sulfide detector. Testing indicated that poor detector temperature control results in signal changes that appear as drift. This problem was addressed by making slight modifications to the thermal environment of the optical bench. These design modifications were characterized with respect to the noise and drift by recording the signal stability using a black body reference standard for a radiation source.

\section{$2.1 \quad$ Drive System Improvements}

The drive system was redesigned with a belt drive to replace the chain drive. This rendered much smoother operation of the optical bench with minimal rpm variations. A twin core belt was implemented which was originally designed for precision alignment and positioning applications. The belt offers smoother operation than possible with chain and does not have the chordal rise and fall (camming effect) of chain. Additionally the belt does not stretch. Drive system selection consisted of researching vendors to find the best alternatives to the ladder chain and modifying the optical bench to accommodate the new drive components. Compatible drive sprockets were machined to fit on the optical bench. The motor bracket also was modified to accommodate the change in alignment resulting from the use of slightly thicker sprockets.

A highly stable $\left( \pm .4^{\circ} \mathrm{C}\right)$ black body calibration reference, discussed in the following section, facilitated characterization of the baseline performance of the TAS signal noise and drift. Figure 2-1 shows the raw data count signal from the unmodified optical bench with the sensor viewing the black body at $1000^{\circ} \mathrm{C}$. Note that the scale of this and all subsequent figures have greatly expanded raw count scales to highlight small changes. The short term noise is clearly obvious. Figure 2-2 illustrates baseline drift over 24 hours by smoothing out the short term noise.

The use of the precision timing belt greatly smoothed the operation of the optical bench. Figure 2-3 shows the raw data for a 24 hour period with the new belt showing a 3 fold reduction in 


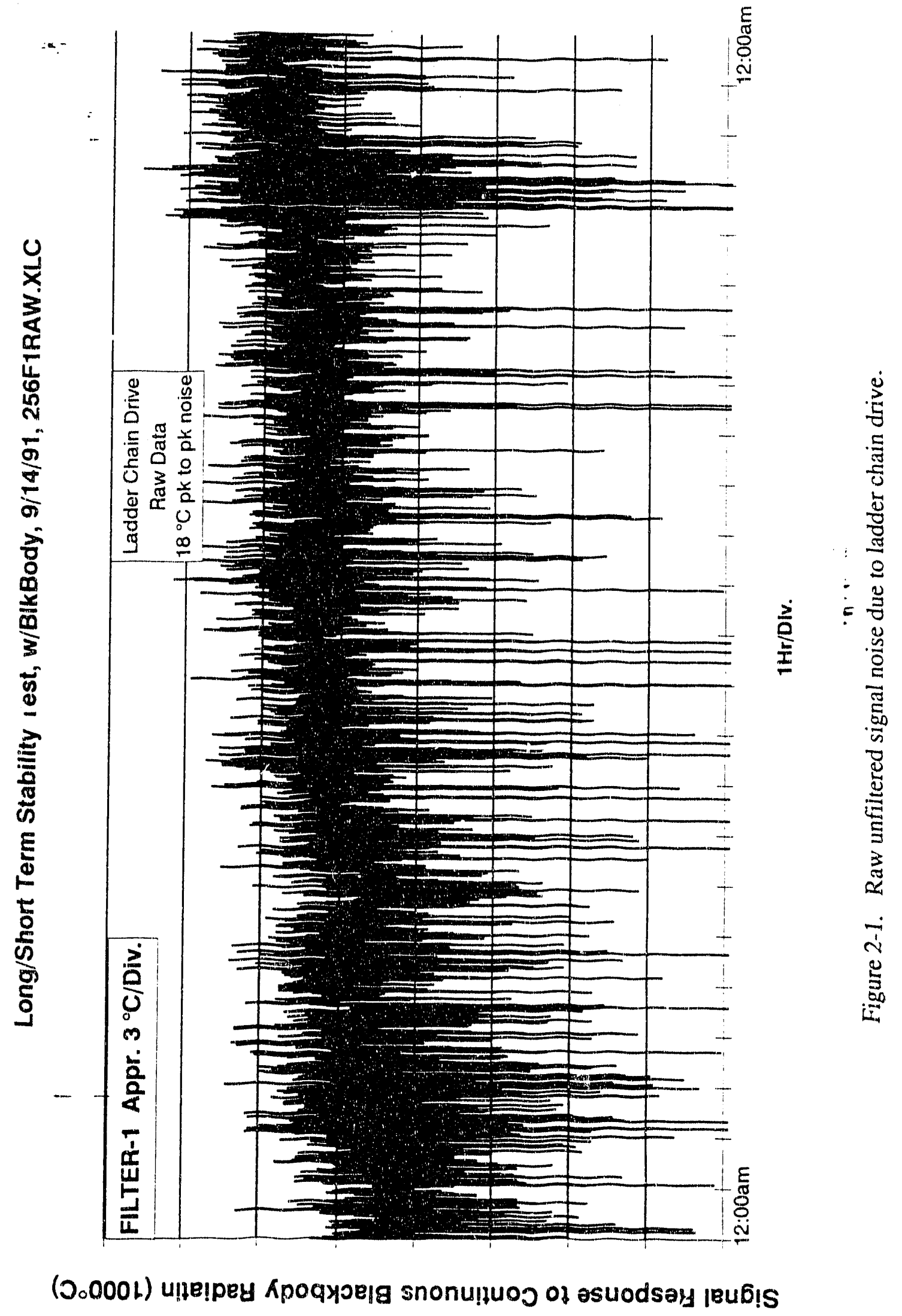




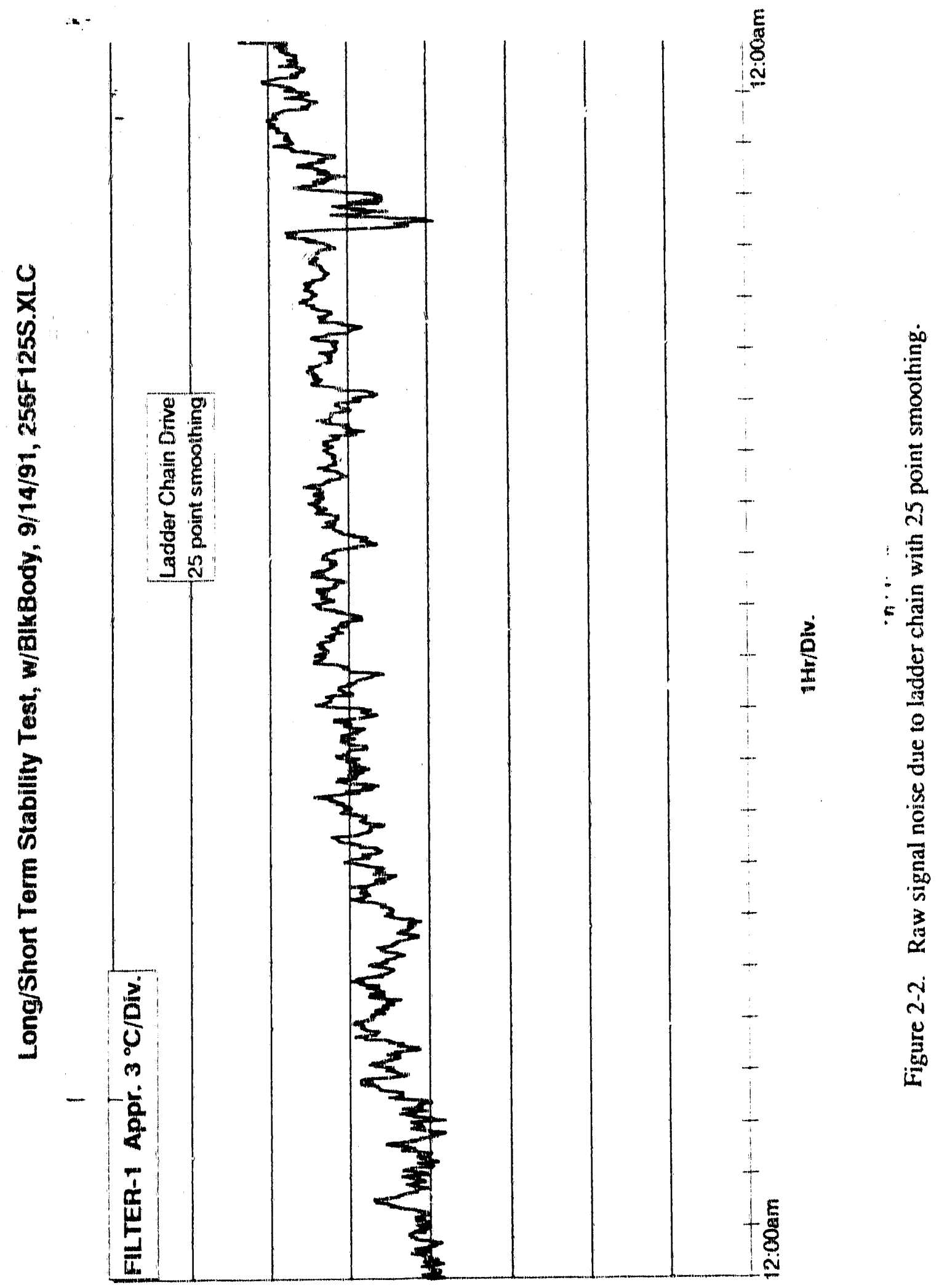

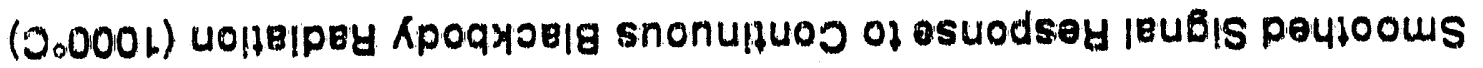




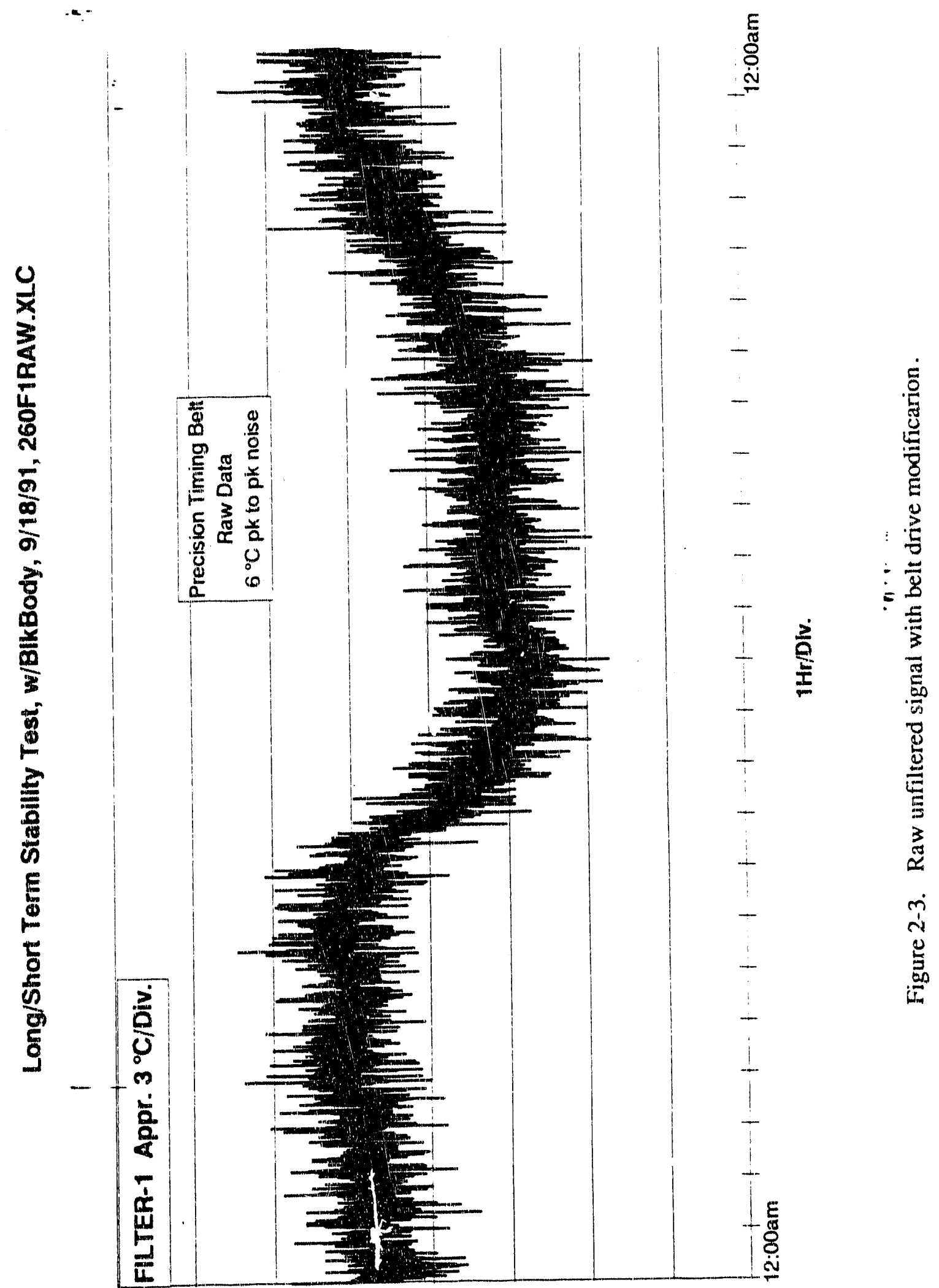

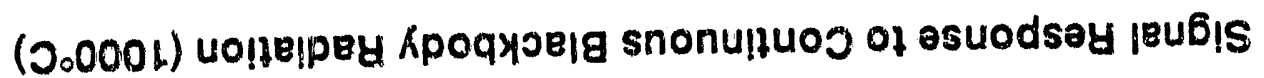


the system short term noise. The drive system improvements did not affect any changes in the system drift. The smoothed signal with the belt drive, Figure $2-4$, shows that the drift is still a significant problem. Through the use of additional digital signal processing, the sysioms short term resolution stability at $1000^{\circ} \mathrm{C}$ has been improved to approximately $\pm 1 / 2{ }^{\circ} \mathrm{C}$. The results of these tests suggest the system drift must be attributable to something other than the optical bench drive system.

System Characistization

Successful characterization of the TAS relied upon finding a stable standardized radiation source capable of $1200^{\circ} \mathrm{C}$ operation to provide a repeatable signal to the sensor optics. A black body reference source was rented from a vendor. The 1.0" diameter aperture source had a stability of $\pm 0.4^{\circ} \mathrm{C}$ (For ambient temperature changes of less than $\pm 5^{\circ} \mathrm{C}$ and line voltage changes of less than $\pm 10 \%$ ). The reference source was used for both short term and long term characterization tests. All characterization studies were conducted with the black body radiation source at $1000^{\circ} \mathrm{C}$ $\left(1832^{\circ} \mathrm{F}\right)$.

Long term stability testing of the TAS was conducted with the sensor viewing the black body reference at $1000^{\circ} \mathrm{C}$ for several 24 hour periods. The results of these tests indicated little improvement in long term drift compared to the Phase I tests or the characterization tests prior to the design modifications. During a 24 hour period, the signal would drift over a range of approximately $\pm 3{ }^{\circ} \mathrm{C}$ (Figure $2 \cdot 4$ shows a typical day). After several days of testing a pattern emerged that suggested the measured temperature was related to ambient temperature variations in the Lab.

A test plan was developed to isolate and identify thermally sensitive components of the TAS. Small sections of the system, (i.e., Sensor Head, Optical Bench, Electronics, etc.) were subjected to temperature extremes through the use of a small heat gun and a freon mist spray. The effect, if any, on the signal output was observed. The results of this test showed that the optical bench and the optical fiber had a measurable and sometimes significant temperature sensitivity.

Thermal expansion of the optical bench could result in small changes in the relative positions between the lenses and detector. These changes will vary the spot size of the infrared radiation incident on the detector, thus affecting the detector output proportionally. Although this type of error was previously believed to be negligible, a worst case optical path analysis showed a 


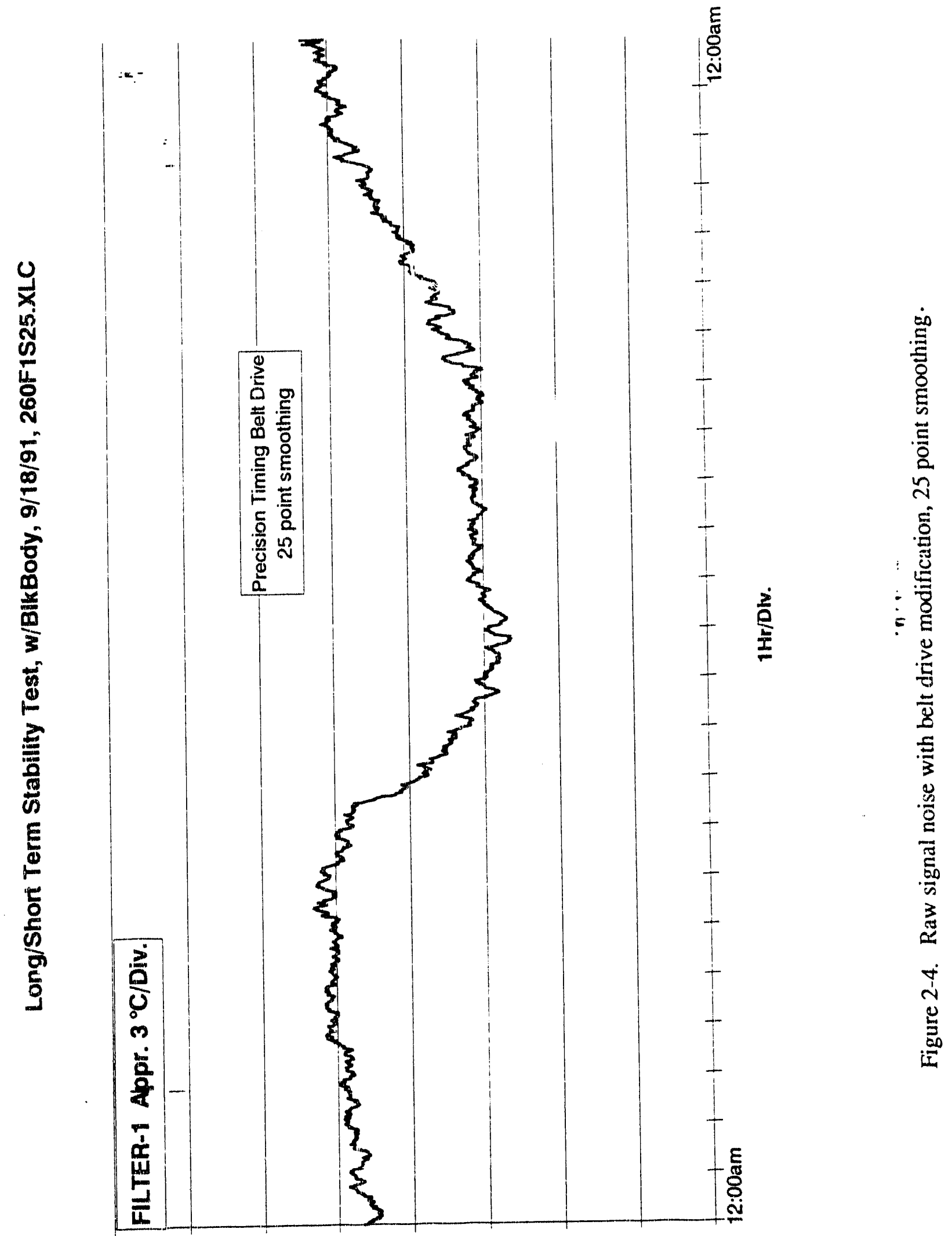

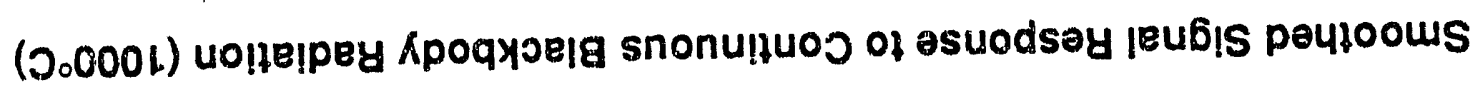


surprising result. $A$ change in optical bench temperature of $3{ }^{\circ} \mathrm{C}$ could result in a $0.5 \%\left(3{ }^{\circ} \mathrm{C}\right.$ at $1000^{\circ} \mathrm{C}$ ) change in detector signal level.

Further testing was conducted to determine the effect of changes in the ambient (external) temperature on optical fiber transmittance. It was expected the thermal effects would be minimal, though as a result of the high degree of precision required of the TAS it was known that a $0.5 \%$ change in transmittance could result in a measurable error in the system. Uncontrolled 'shock' tests were performed on the fiber by heating approximately 7 meters of the fiber with a heat gun. Results of these tests, which are quantitatively estimated in Table 2-1, showed there was a measurable thermal effect at all wavelengths and that F4 $(4.0 \mu \mathrm{m})$ was the most strongly influenced. Figure 2-5 shows this is likely attributable to the steep slope of the attenuation curve at that wavelength. For all practical purposes, with the exception of F4, the thermal effects of the fiber could be calibrated out in a typical operating environment.

TABLE 2-1. OPTICAL FIBER THERMAL ERROR

Filter Wavelength

F1 $(2.4 \mu \mathrm{m})$

F2 $(2.6 \mu \mathrm{m})$

F3 $(3.5 \mu \mathrm{m})$

F4 $(4.0 \mu \mathrm{m})$

\section{Estimated Optical Fiber Error}

(chg in reading/chg in fiber temp-unit length)

The error effect and thermal stability of the detector thermo-electric cooler (TEC) was characterized by recording the thermo-electric cooler (TEC) thermistor voltage and hence the detector temperature, and by characterizing the output error caused by an induced change in the detector temperature. The latter was acccmplished by changing the current to the TEC. The results are shown in Table 2-2 below. 


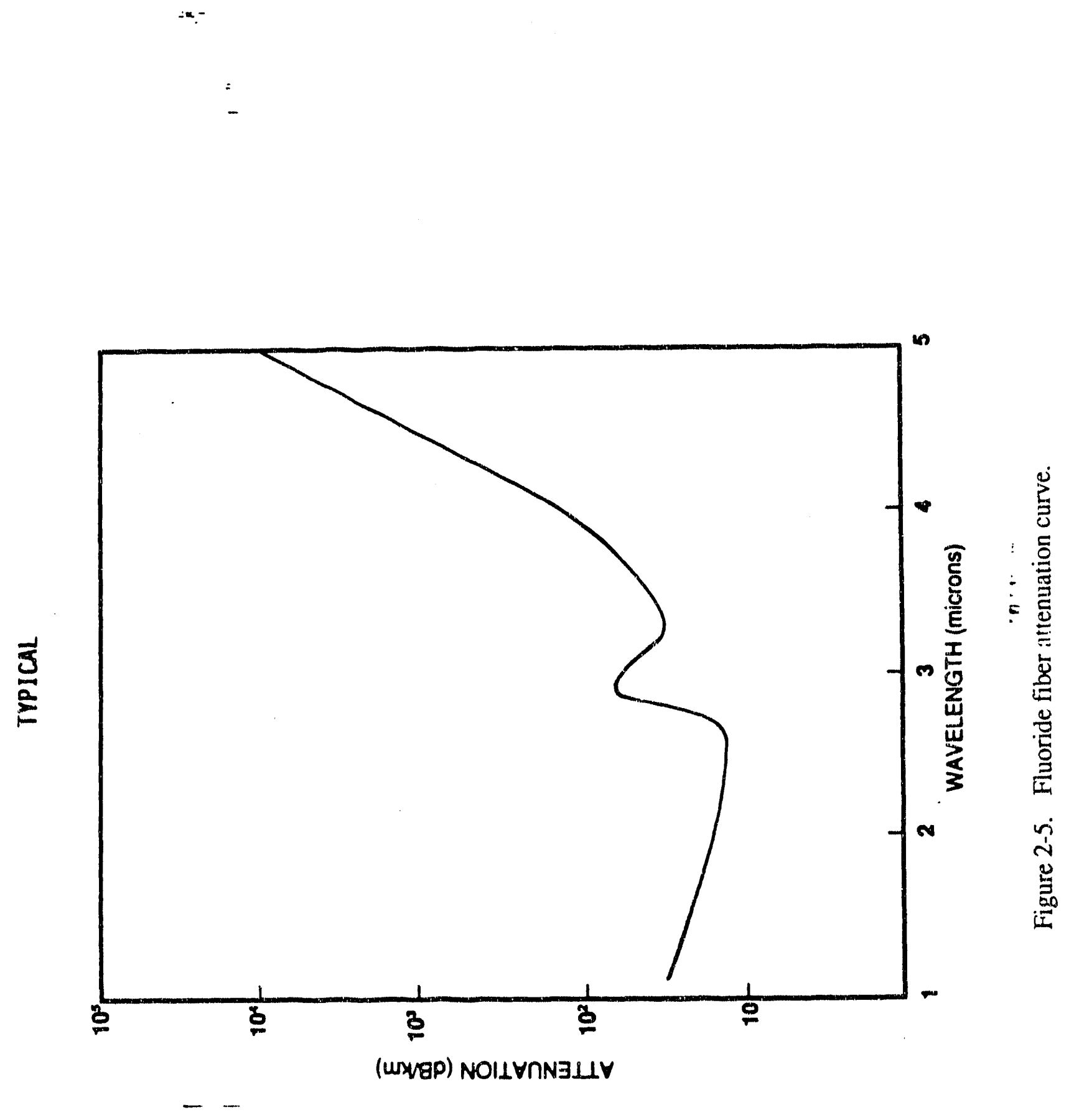




\section{TABLE 2-2. TEC STABILITY AND ERROR}

$\begin{array}{cc}\text { Filter Wavelength } \\ & = \\ \text { F1 } & (2.4 \mu \mathrm{m}) \\ \text { F2 } & (2.6 \mu \mathrm{m}) \\ \text { F3 } & (3.5 \mu \mathrm{m}) \\ \text { F4 } & (4.0 \mu \mathrm{m})\end{array}$

TEC Thermal Error
(chg in reading/TEC temp chg)
$-7.2^{\circ} \mathrm{C} /{ }^{\circ} \mathrm{C}$
$-8.0^{\circ} \mathrm{C} / \mathrm{C}$
$-10.0^{\circ} \mathrm{C} / \mathrm{C}$
$-11.6^{\circ} \mathrm{C} /{ }^{\circ} \mathrm{C}$.

TAS Output Stability
$\left(@ \mathrm{TEC} \pm 0.05^{\circ} \mathrm{C}\right)$
$\pm 0.36^{\circ} \mathrm{C}$
$\pm 0.40^{\circ} \mathrm{C}$
$\pm 0.50^{\circ} \mathrm{C}$
$\pm 0.58^{\circ} \mathrm{C}$

The results show the potential error due to TEC instability to be significant, though stability tests show the TEC temperature to be within $\pm 0.05^{\circ} \mathrm{C}$ at normal operating conditions, thus implying this effect is not a significant source of drift.

Another component believed to be contributing to the drift is the accuracy of the black body calibration source. Whereas the short term accuracy of the black body calibration source is \pm 0.4 ${ }^{\circ} \mathrm{C}$, its long term stability is only $\pm 1{ }^{\circ} \mathrm{C}$, which is of the same order of the accuracy we are trying to achieve. In summary, the characterization studies have shown that system drift can be attributed to $=$ the compound thermal effects of the black body reference stability, and the ambient temperature sensitivity of the optical bench, the optical fiber, and to a lessor degree the detector TEC.

\section{$2.3 \quad$ Enclosure Thermal Control}

Several methods to fix the optical bench's temperature sensitivity were considered. In the long run, the best solution would be to construct the bench out of a material with a small thermal expansion coefficient. Unfortunately, the current program budget did not allow for this option. Instead, a low cost temporary solution was developed.

The optical bench and the TAS electronics are housed in a sealed, NEMA 4 enclosure. A Vortec tube (compressed air cooling device) was attached to the enclosure and a temperature controlled electrical heating element was placed inside. The Vortec tube provided brute force cooling while the heating element would back heat to a precise temperature. With this simple arrangement of off-the-shelf components temperature inside the enclosure was maintained to $\pm 1{ }^{\circ} \mathrm{C}$ over wide ambient swings and was more typically $\pm 1 / 2^{\circ} \mathrm{C}$. 
Additional tests were conducted using the temperature controlled system. The first such test was to accurately characterize the optical bench's temperature sensitivity. The enclosure's temperature set-point was changed in steps by $10-15^{\circ} \mathrm{C}$ and changes in TAS output were recorded. The results of this test are shown in Table 2-3 below. They track very well with the theoretical error calculations.

TABLE 2-3. OPTICAL BENCH THERMAL ERROR

$\begin{array}{ll}\text { Filter Wavelength } \\ \text { F1 } & (2.4 \mu \mathrm{m}) \\ \text { F2 } & (2.6 \mu \mathrm{m}) \\ \text { F3 } & (3.5 \mu \mathrm{m}) \\ \text { F4 } & (4.0 \mu \mathrm{m})\end{array}$

Q.B. Error
(chg in reading/chg in bench temp)
$-0.62^{\circ} \mathrm{C} /{ }^{\circ} \mathrm{C}$
$-0.85^{\circ} \mathrm{C}^{\circ} \mathrm{C}$
$-0.80^{\circ} \mathrm{C} /{ }^{\circ} \mathrm{C}$
$-1.04^{\circ} \mathrm{C}^{\circ} \mathrm{C}$

A long term, 7 day stability test was conducted using the temperature controlled system. The results of this test are shown in Figure 2-6. Surprisingly, the system still appears to drift about \pm $3^{\circ} \mathrm{C}$. A detailed analysis, however, reveals another possible explanation. First, it should be noted, when the system was placed in the temperature controlled enclosure, it was necessary to move all of the test apparatus from a small air conditioned development lab to EER's larger but un-airconditioned main lab. Temperature swings in the development lab were on the order of $5^{\circ} \mathrm{C}$, while the main lab swing was as much as $15-20^{\circ} \mathrm{C}$. The optical bench was in a controlled enclosure, but the black body source and the fiber were not. To lower temperature swings on the optical fiber, exhaust air from the controlled enclosure was directed into and through the conduit containing the optical fiber (fiber temperature variations are shown in Figure 2-6). This proved effective in controlling the fiber temperature to an acceptable level, but nothing could be done to temperature control the black body source.

The top part of Figure 2-6 shows the fiber temperature recorded along with the optical measurement. The fiber temperature swing is about $1 / 2$ that of the ambient, which would put the ambient swing at about $15^{\circ} \mathrm{C}$. That is 3 times greater than the black body requires for stable operation. The cyclic nature of the TAS drift is clearly the result of ambient temperature fluctuations but attempts to directly compensate for the error were unsuccessful. This is most likely because the black body controller over compensates at some points and under compensates at other times. 


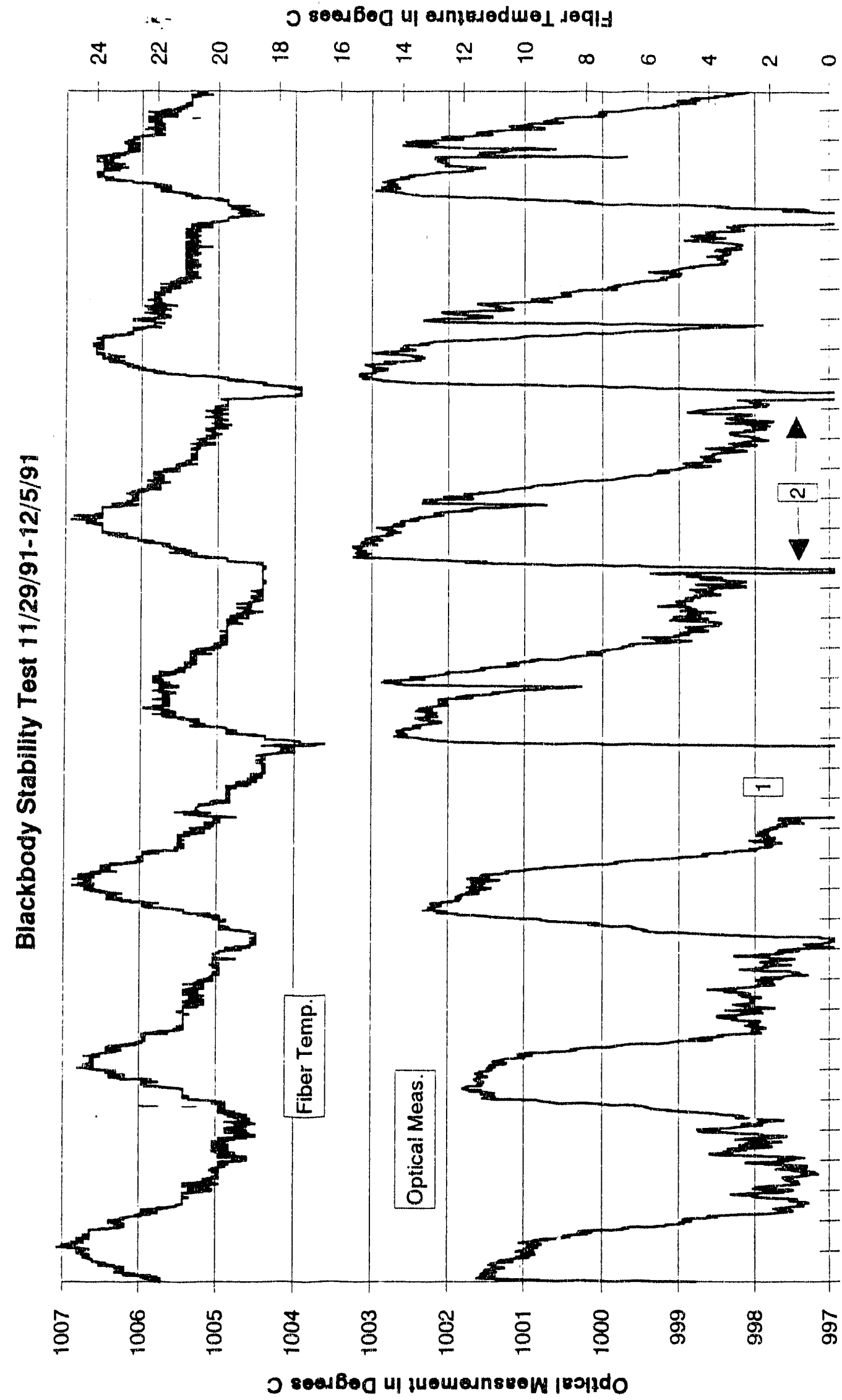

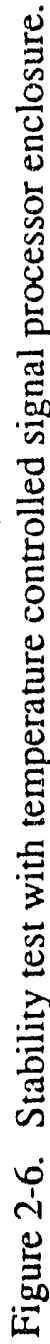


The evidence for this assumption may be found at legend 2 on Figure 2-6. The sharp spikes down the optical measurement for these two days (Tuesday and Wednesday) exactly coincide with the 6:30 am opening of the bay doors to EER's main lab area. Then, very quickly, even while the ambient temperature is still low, the optical measurement quickly rises toward a peak. This is typical of the type of response that would be expected from the blackbody controller. Legend 1 of Figure 2-6 is a point where power failed to the lab air compressor. Data was not valid during this time.

The conclusion we draw from this data is that the blackbody source was the cause of most of the drift recorded in this test. In general, the Optical Measurement was cyclically stable (i.e. peak vs. peak, valley vs. valley) $\pm 1^{\circ} \mathrm{C}$. During periods of time when the temperature was most stable, (usually just before dawn) the measurement was stable $\pm 1 / 2{ }^{\circ} \mathrm{C}$. Additionally the measurement returned to the same point each morning just before dawn $\pm 1 / 2{ }^{\circ} \mathrm{C}$, which suggests that there was no measurable long term drift over the seven day test period. 
The calibration source developed in the previous Phase 1, Task 2 while functional, was not practical for field use. ${ }^{-}$The goal of this task was to design and develop a calibration source that is compact and integrated with the sensor head, Figure 3-4. The calibration source would be used to correct for the previously described temperature sensitivities as well as longer term changes in optical transmission and component efficiencies.

A calibration method capable of detecting and compensating for losses in the optical path from sensor to detector is desirable. The system should be ultimately based on a black body calibration traceable to NIST methods or standards. NIST traceable black body calibrators with operation greater than $600^{\circ} \mathrm{C}$ are typically quite large, being at least 12 ' $\mathrm{L} \times 8^{\prime \prime} \mathrm{W} \times 8^{\prime \prime} \mathrm{H}$, and cost in excess of $\$ 5000$. Therefore, several design concepts employing a secondary standard which is miniaturized and integrated into the sensor were evaluated. The calibrator system requires the following attributes: compact design, mininal power requirement, high stability, low drift, low: cost, and certification against a primary standard.

\subsection{Calibration Concept Evaluation}

Several concepts for on line calibration of the TAS sensors were conceptualized and considered possible candidates for development. The four basic concepts considered were: moveable in-furnace calibration target, internal high surface area heating element, in-situ heated wire, and internal moveable lamp. Each of these concepts were evaluated from the stand point of cost, complexity, materials feasibility, reliability, signal stability, signal strength, and power requirements. The following paragraphs describe each of the four concepts considered for the calibration scherne:

Concept 1: Moveable In Furnace Calibration Target: This concept is founded on the idea that the internal furnace energy could be used as an energy source to heat a surface which could be used to calibrate the system. The temperature instrumented surface would be made of some high emissivity material such as silicon carbide and could be installed in such a way as to be able to be switched in and out of the view of the sensor. 
Concept 2;-Internal High Surface-Area Heating Element: This idea is aimed at finding a heating element which is large enough to fill a significant portion of the sensor view and could be heated up in the view of the sensor. This element could either be moved into view during calibration or could be positioned outside of the operative area but within the internal view of the sensor collecting mirror. This concept would offer a good signal level.

Concept 3: In-situ Heated Wire: This concept is similar to concept 2 above, however, the element would be a wire with much less surface area. In this case, the wire would be strung across the field of view of the sensor obstructing a very small amount of the field of view. The benefit of this method is the absence of moving parts.

Concept 4: Internal Moveable Lamp: This concept is similar to concept 2 in that the element would either be movable or out of the aperture limited field of view. The difference here is that the element would be a lamp which is capable of much higher surface temperature i.e.: signal level, than an unprotected heating element.

Evaluation of Concept 1 centered on a heat transfer analysis of the temperature stability of a disc being moved in and out of the sensor view. The interior of the forehearth cannot be assumed to be isothermal and in the region near an open port or cold surface (such as a cooled sensor head) thermal gradients will be significant. The temperature of a calibration target in close proximity to the cooled end of the sensor head will be strongly influenced by its positioning and geometric shape relative to the sensor. The heat transfer analysis showed for a 1 " diameter calibration surface 1 "from the sensor tip, the effect of moving the surface in and out of the sensor view would result in a $40^{\circ} \mathrm{F}\left(23^{\circ} \mathrm{C}\right)$ change in the surface temperature.

The instability of the surface temperature combined with the dynamic thermal changes incurred by the gas jets in the forehearth would combine to make an internal calibration target unsuitable for a repeatable calibration source. Even a thermocouple monitored target would require extensive characterization in the furnace and such a system does not lend itself to off line calibration.

The in-situ heated wire concept was dismissed because the minimum radiance requirement for minimum acceptable signal to noise level could not be met by the small surface area of a wire. Concept 4 was evaluated by testing the stability of several miniature precision lamps. These lamps 
operated at surface temperatures as high as $2800^{\circ} \mathrm{C}$ however the small size of the filaments did not facilitate adequate signal to satisfy the minimum radiance requirement.

The most promising concept was determined to be concept 2 which uses an in-situ hot ceramic element $\left(1200^{\circ} \mathrm{C}\right)$ as a calibration source and which is moved into the sensor view during the calibration sequence. The elements tested for this concept were a silicon nitride heater and a ceramic-metallic composite that could be heated in excess of $1200^{\circ} \mathrm{C}$ in $10-20 \mathrm{sec}$. Testing of the elements were conducted to determine iong term stability of the element temperature and emissivity and are discussed in the following section.

\section{$3.2 \quad$ Element Testing}

Vendors were searched for inexpensive heating elements to be used as a repeatable calibration sources in the sensors. The search revealed a number of different types of small heating elements, Table 3-1 below.

TABLE 3-1. HEATING ELEMENTS

$\begin{array}{lllll}\text { Mfg } & \text { Element Type } & \text { Power } & \text { Typ Temp } & \text { Geometry } \\ \text { Norton } & \text { Cermet } & 24 \mathrm{~V} / 40 \mathrm{~W} & 1300^{\circ} \mathrm{C} & \text { Flat } \\ \text { Norton } & \text { SiC } & 120 \mathrm{~V} / 500 \mathrm{~W} & 1400^{\circ} \mathrm{C} & \text { Flat } \\ \text { Kyocera } & \begin{array}{l}\text { Alumina } \\ \text { Encapsulated } \\ \text { Metal Film }\end{array} & 90 \mathrm{~V} / 40 \mathrm{~W} & 800^{\circ} \mathrm{C} & \text { Custom } \\ \text { Kyocera } & \begin{array}{l}\text { SiliconNitride } \\ \text { Encapsulated }\end{array} & 90 \mathrm{~V} / 40 \mathrm{~W} & 1200^{\circ} \mathrm{C} & \text { Custom } \\ & \text { Metal Film } & & & \\ \text { White-Rodgers } & \text { SiC } & 120 \mathrm{~V} / 500 \mathrm{~W} & 1400^{\circ} \mathrm{C} & \text { Coil }\end{array}$

Review of the available miniature high temperature heating elements on the market indicated that silicon carbide (SIC) elements have very high power requirements. The silicon carbide elements listed in Table 3-1 operate at 500 watts. This requires over 4 amperes of current which was determined to be undesirable for the 20 meter sensor cabling distance. The Norton Cermet and Kyocera units are recent innovations and have lower power and current requirements. Both offer compact packaging and fast heat -up $(6-12 \mathrm{sec})$. The Norton Cermet is a ceramic-metallic composite which is electricly conductive and oxidation resistant. The Kyocera elements are made 
of either alumina or silicon nitride which could potentially have the greatest resistance to oxidation related emissivity degradation. Both the Norton Cermet and Kyocera elements were believed to be excellent candidates for a miniature calibration source.

Initial cycle testing of the elements entailed using a cycle timer to control power to the elements and monitoring the peak signal levels over a 24 hour or more period. The duty cycle used for testing was approximately 3 minutes on followed by 6 minutes off. The Norton heater was tested at its operating voltage $(24 \mathrm{~V})$ and over the initial 15 hours of operation was found to have significant decay as shown in Figure 3-1. The decay was thought to be attributable to a burn in period so the test was conducted again after letting the igniter "burn in" continuously for an additional two days. The second test showed a less severe but still significant decay $\left(0.15^{\circ} \mathrm{C} / \mathrm{hr}\right)$ as seen in Figure 3-2.

The Kyocera silicon nitride glow plug was cycle tested in the same manner as the Norton heater. More difficulty in testing this element was encountered because of its higher voltage requirement. EER did not have a regulated power supply to operate the element so initial testing was conducted using line voltage with a variac. This testing showed large variations in signal and was determined to be inconclusive due to the unregulated nature of the power supply. A regulated power supply configuration was assembled having an accuracy of $\pm 1 \%$. These tests yielded promising but inconclusive results. The silicon nitride heater gave signals with significant variations though there was no discernable trend indicating element degradation. This data is given in Figure 3-3.

Further testing was conducted with the element installed on the calibration assembly yielding more applications oriented test results. This testing is discussed in the following section.

A mechanical assembly was designed to hold the calibration element and to move it in and out of the opticalpath of the sensor during the calibration cycle. Three key characteristics were required of the assembly. These were repeatable positioning of the element in the sensor field of view, the ability to accommodate the heating elements under consideration, and to isolate the element from air currents. A prototype platform was fabricated and assembled and is shown in Figure 3-4. It employs a slide assembly on which the element is attached and an air cylinder to move the slide back and forth. A cycle timer activates the power to the element and a solenoid piloted switch which positions the slide air cylinder. For this part of testing EER acquired a 


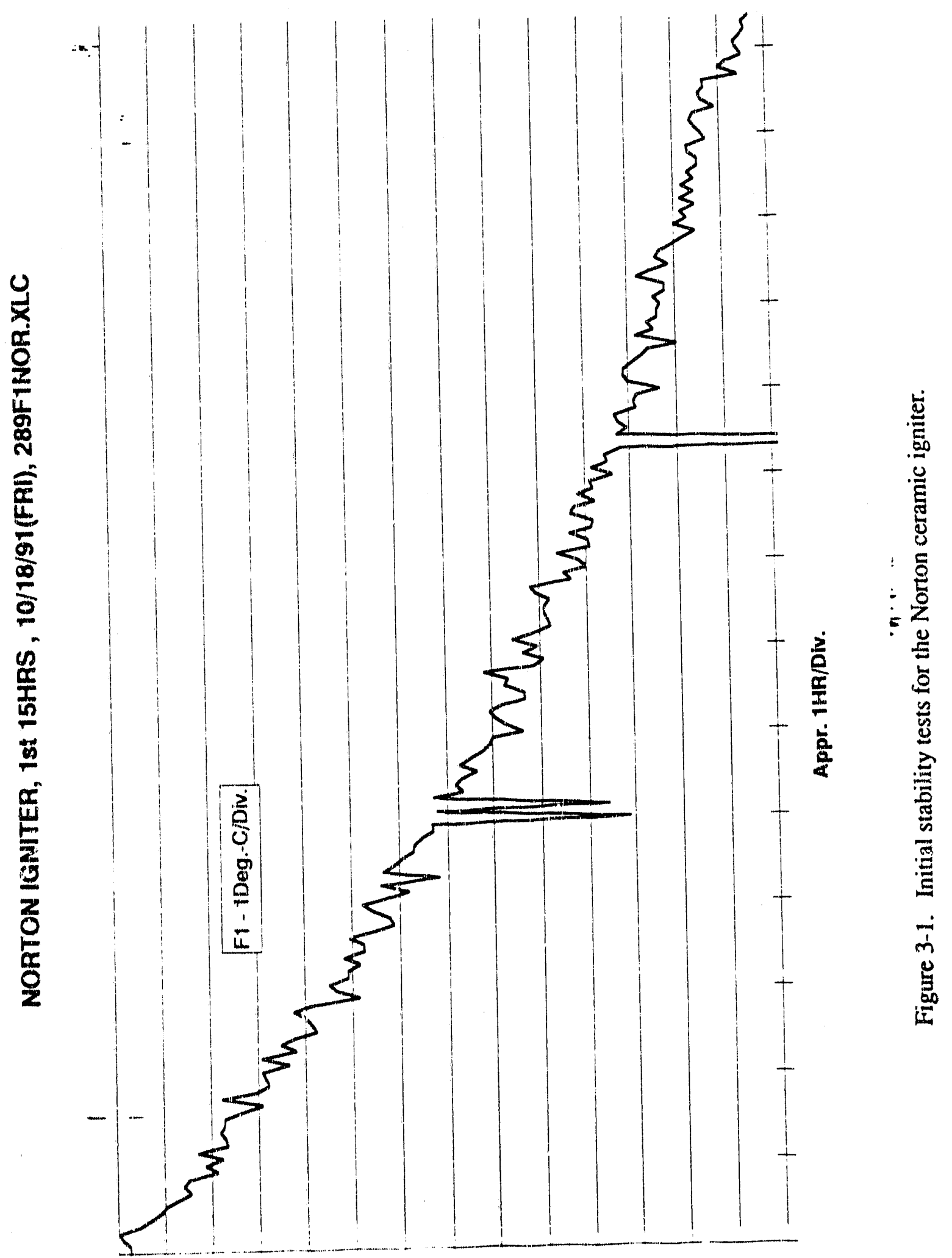

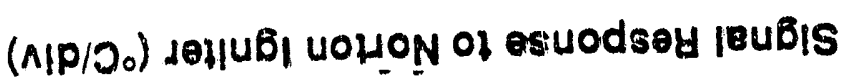




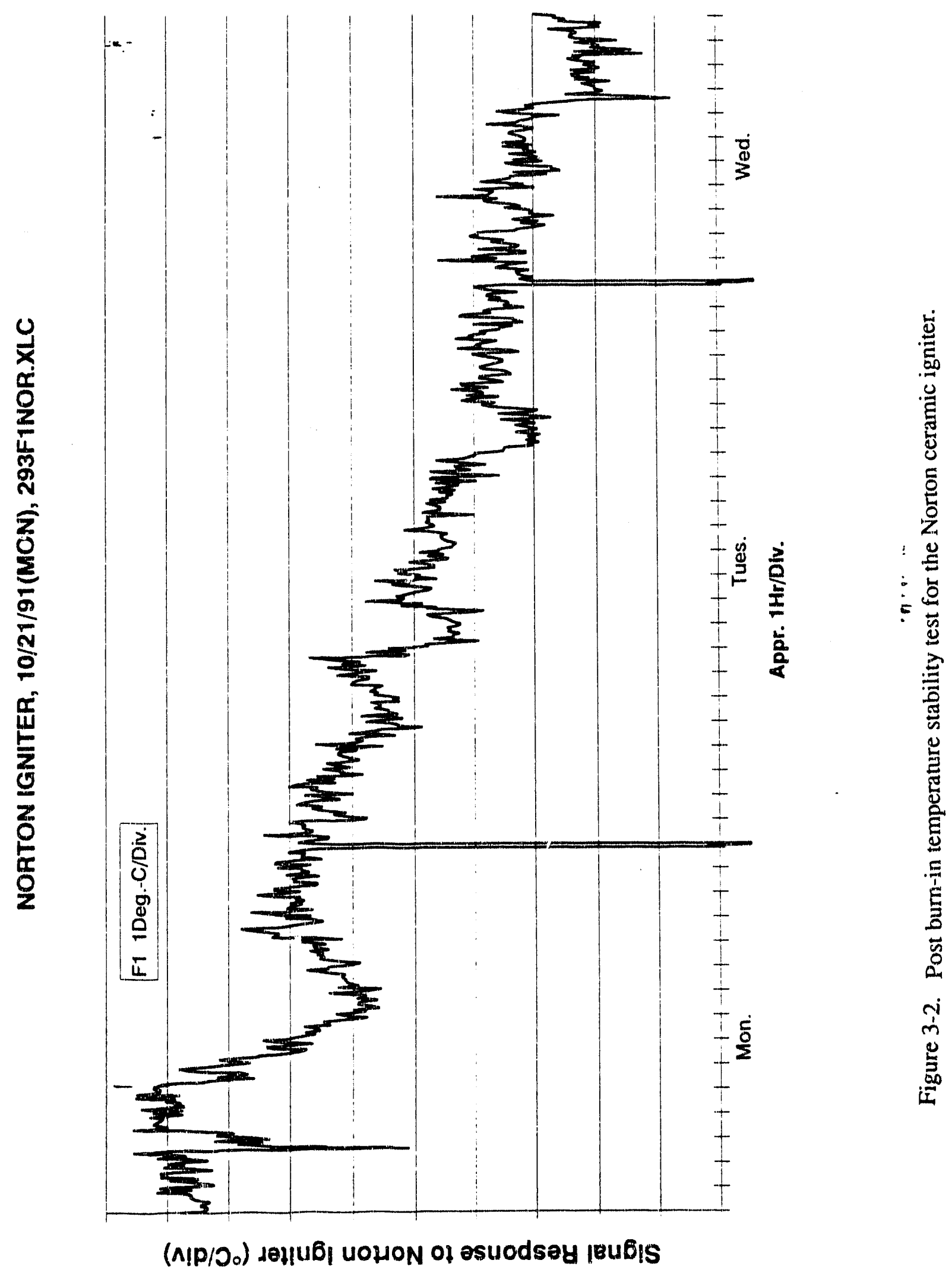




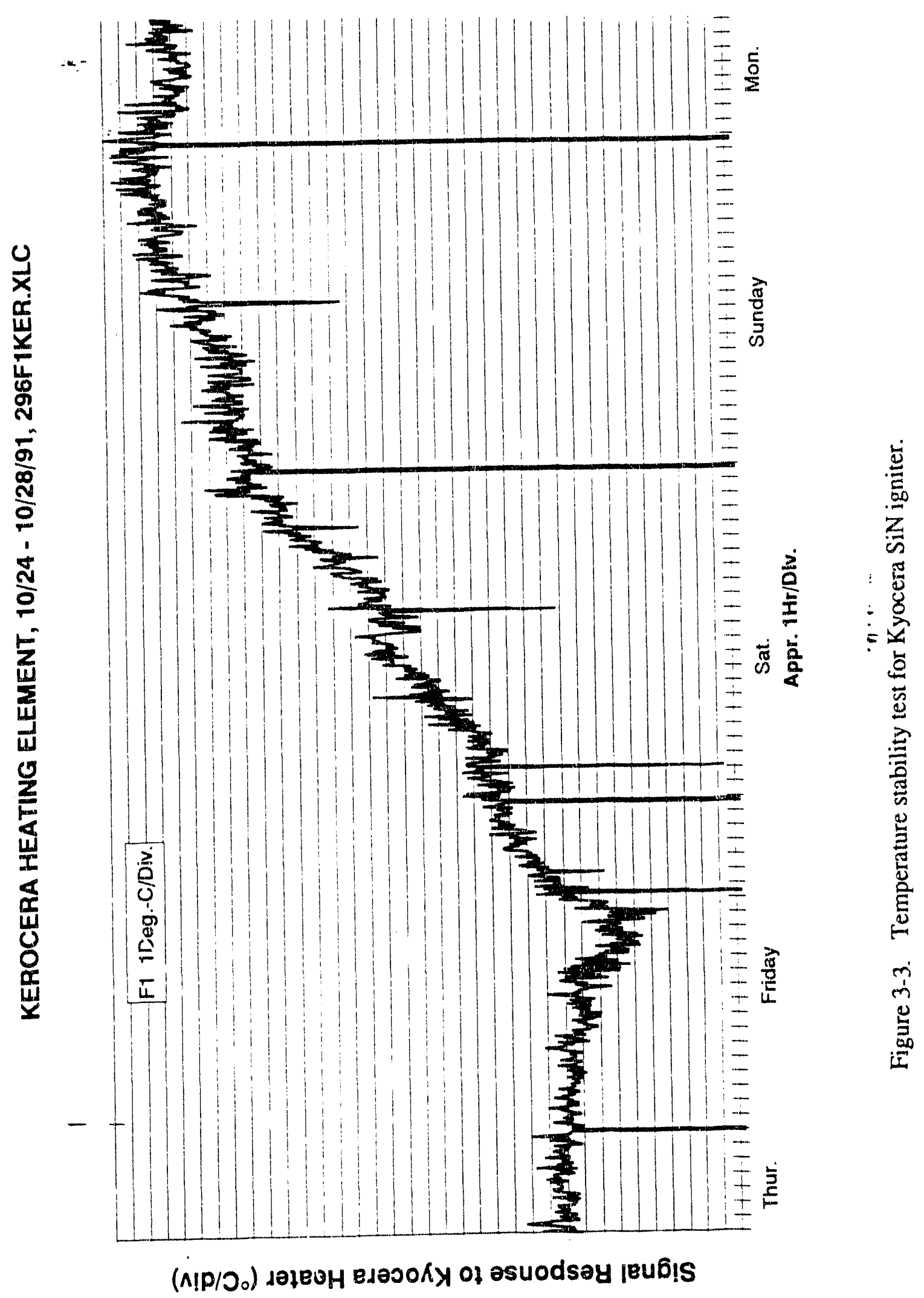




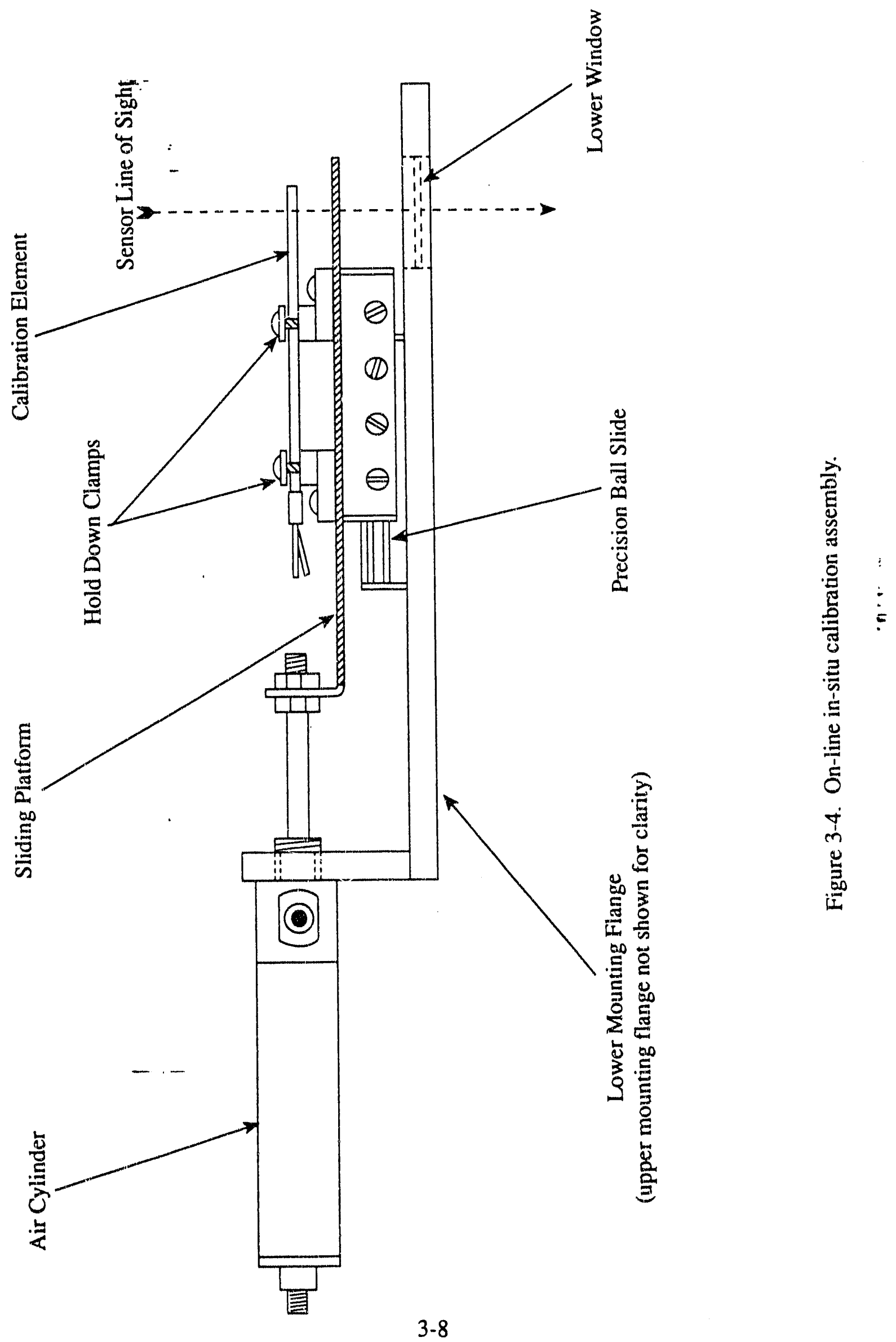


regulated $D C$ power supply to provide $\pm 0.5 \%$ power to the element. The element was tested for temperature sensit Thus small changes in supply voltage will not cause dramatic errors in calibration. Further cycle testing of the Kyocera SiN heater on the slide assembly showed unacceptable degradation in signal followed by element failure. It is believed the element may have been damaged in the testing sequence prior to the final cycle test.

Further cycle tests were performed using the alumina Kyocera heater on line with the sensor measuring glass melt temperatures. In order to compensate for the observed signal degradation a bare tip thermocouple was attached to the element to measure element temperature.

The element was first calibrated against the black body reference and then moved to the furnace for testing. The calibration assembly operated very well in service however the thermocouple did not maintain contact with the element surface. Thus the stability of the element can not be asjured. Since additional development is indicated and funds for this task were expended, work was suspended and the pilot furnace tests were initiated. 


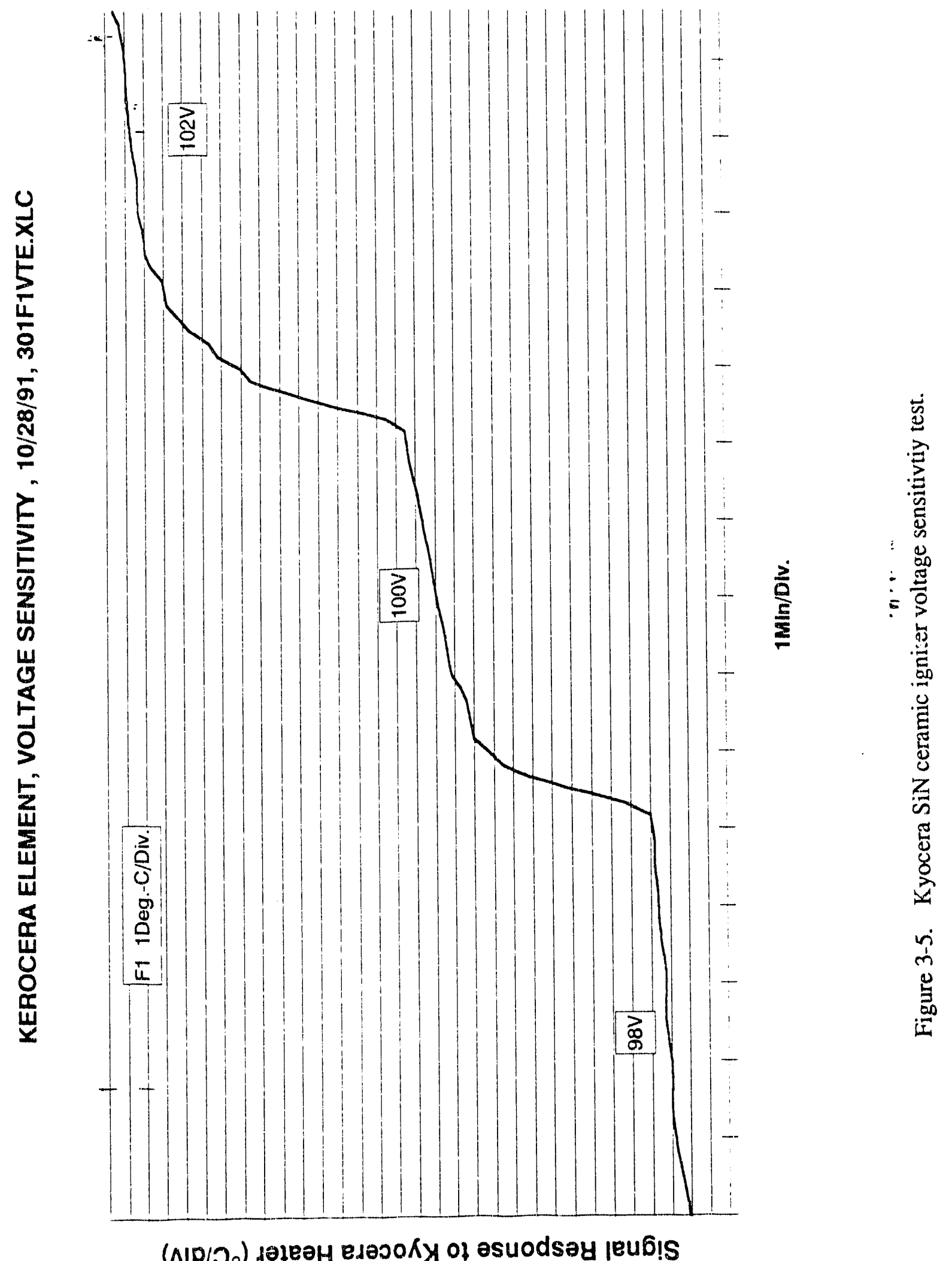


Using the redesigned system components and improved firmware. Isothermal and temperature gradient tēsts were performed on glass samples in the same manner as the previous laboratory testing (Task 4). The effect of one of the potentially important factors used to determine the temperature in glass, emissivity was concurrently studied. Varying levels of contaminants such as iron, lead or soda can conceivably change the emissivity of the glass. Tests were conducted to determine what effect, if any, these variations have on emissivity. Two samples of each of three different glass types were obtained. Each of these samples were analyzed by an outside lab to determine their compositions. The results of these tests are shown in Table 4-1. Due to the confidential nature of the glass compositions only the constituents of interest, such as iron, soda and chrome are indicated. The composition standard deviations were furnished by Gallo in confidence for their glasses. This information served as a basis for determining the significance of variations between similar glass samples and permitted accurate statistical analysis of variations. The analysis indicated that the differences between the similar samples were statistically significant. The emissivity of each glass was measured and the resulting effects on temperature measurement. were analyzed. The gradient tests were designed to demonstrate the ability to measure temperatureof the glass at depth.

\section{$4.1 \quad$ Test Plan}

The process simulation (Pilot Scale) tests were conducted in the same manner as before 1. The glass samples were melted in zirconium oxide crucibles and the sensor was aimed at the glass surface at a $90^{\circ}$ angle through the furnace roof. The temperature of the glass was monitored with two triplex thermocouples.

The test plan was designed to meet two goals with the modified system, to determine the effect of glass composition on emissivity and to measure glass temperature at depth. In order to meet the first objective, samples of glass with varying compositions were needed. The glasses used in previous pilot testing were Gallo Champagne Green, and flint from both Gallo and Kerr. All of these samples, predominantly raw glass, were obtained in September of 1990 . New samples, predominantly finished product and potentially of different composition, Table 4-1, have some differences in composition relative to their three year standard deviation. 


\section{-.- TABLE 4-1. GLASS ANALYSIS RESULTS}

\begin{tabular}{|c|c|c|c|c|c|c|}
\hline & & \multicolumn{5}{|c|}{ Constituent Species, \% } \\
\hline Glass Type & Date & $\mathrm{SiO}_{2}$ & $\mathrm{Na}_{2} \mathrm{O}$ & $\mathrm{Fe}_{2} \mathrm{O}_{3}$ & $\mathrm{Cr}_{2} \mathrm{O}_{3}$ & $\mathrm{CaO}$ \\
\hline $\begin{array}{r}\text { Gallo Green } \\
\text { Sample } 1 \\
\text { Sample } 2\end{array}$ & $\begin{array}{l}\text { Sept. } 1990 \\
\text { Sept. } 1991\end{array}$ & $\begin{array}{l}70.87 \\
71.15\end{array}$ & $\begin{array}{l}13.16 \\
13.32\end{array}$ & $\begin{array}{l}0.227 \\
0.233\end{array}$ & $\begin{array}{l}0.181 \\
0.215\end{array}$ & $\begin{array}{l}10.17 \\
9.48\end{array}$ \\
\hline $\begin{array}{l}\text { Gallo Flint } \\
\text { Sample } 1 \\
\text { Sample } 2\end{array}$ & $\begin{array}{l}\text { Sept. } 1990 \\
\text { Sept. } 1991\end{array}$ & $\begin{array}{l}70.43 \\
70.63\end{array}$ & $\begin{array}{l}12.85 \\
13.06\end{array}$ & $\begin{array}{l}0.138 \\
0.117\end{array}$ & - & $\begin{array}{l}10.58 \\
10.39\end{array}$ \\
\hline $\begin{array}{l}\text { Kerr Flint } \\
\text { Sample } 1 \\
\text { Sample } 2\end{array}$ & $\begin{array}{l}\text { Sept. } 1990 \\
\text { Sept. } 1991\end{array}$ & $\begin{array}{l}72.06 \\
71.97\end{array}$ & $\begin{array}{l}\overline{1} .71 \\
13.76\end{array}$ & $\begin{array}{l}0.051 \\
0.062\end{array}$ & $\begin{array}{l}- \\
- \\
-\end{array}$ & $\begin{array}{l}- \\
10.86 \\
10.91\end{array}$ \\
\hline
\end{tabular}

The standard deviation for the Gallo glasses were given by Gallo in confidence to EER. That data, which is not shown, is representative of composition variations over a 3 year period (1988 - 1990) and is monitored for glass quality control. Comparison between the standard deviation and the differences between 1990 and 1991 compositional levels indicate the samples are, for the constituents of interest, statistically different but were not examples of extreme variations. The differences were though to be significant enough for evaluation of emissivity variations.

The test matrix was designed to evaluate the emissivities of each of the six glass samples and to measure glass temperature at depth for each of the three different glass types. The emissivity measurements were conducted with the glass sample at a relatively isothermal state and the depth measurements were made with the glass under an induced gradient. Table 4-2 gives the text matrix for the Phase 1A pilot scale tests. 
TABLE 4-2. PLOT SCALE TEST MATRIX - PHASE 1A

\begin{tabular}{|c|c|c|c|}
\hline Glass & Sample & Thermal State & $\frac{\text { Temperature }}{{ }^{\circ} \mathrm{F}}$ \\
\hline \multirow[t]{3}{*}{ Kerr Flint } & Sample 2 & Gradient & $\begin{array}{l}1840 \\
1940\end{array}$ \\
\hline & Sample 2 & Isothermal & $\begin{array}{l}1840 \\
1940 \\
2040\end{array}$ \\
\hline & Sample 1 & Isothermal & $\begin{array}{l}1840 \\
1940 \\
2040\end{array}$ \\
\hline \multirow[t]{3}{*}{ Gallo Green } & Sample 2 & Gradient & $\begin{array}{l}1840 \\
1940\end{array}$ \\
\hline & Sample 2 & Isothermal & $\begin{array}{l}1840 \\
1940 \\
2040\end{array}$ \\
\hline & Sample 1 & Isothermal & $\begin{array}{l}1840 \\
1940 \\
2040\end{array}$ \\
\hline \multirow[t]{3}{*}{ Gallo Flint } & Sample 2 & Gradient & $\begin{array}{l}1840 \\
1940\end{array}$ \\
\hline & Sample 2 & Isothermal & $\begin{array}{l}1840 \\
1940 \\
2040\end{array}$ \\
\hline & Sample 1 & Isothermal & $\begin{array}{l}1840 \\
1940 \\
2040\end{array}$ \\
\hline
\end{tabular}

The above matrix was designed to give adequate analysis of the parameters critical to the evaluation of the analyzer.

\section{$4.2 \quad$ Glass Testing}

Pilot scale testing was conducted in the same manner as in the previous Phase I work 1 . Glass samples were melted in a crucible within the box furnace and the glass melt radiant signatires were collected with the modified sensor through view ports in the roof of the furnace. The glass melts were generally 7" deep and $51 / 2$ " in diameter and were thermally monitored with the two triplex thermocouples located 1" to either side of the sensor centerline measurement location. The data acquisition system was also unchanged from before. 
The main components of the data acquisition system were a PC with custom software, the TAS, and multiplexing thermocouple electronics. The PC was used to control the operation of the TAS and to log data:to disk for off-line analysis. Software allowed the operator to choose to record any combination of triplex thermocouple or TAS data. Real-time table and graphic displays were available to assist the operator with pretest setup.

Calibration of the system was performed using the black body reference standard and the insensor calibrator assembly. The procedure used the signal from the black body reference at $1000^{\circ} \mathrm{C}$ to calibrate the strip heater with the analyzer. Subsequent calibrations consisted of compensating the calibration constants in the data reduction spreadsheet by ratiometric changes between the on-line calibration and the baseline calibrations. On-line calibration sequences were conducted during each of the batch glass test runs. The sensor-optics and optical components were not moved in order to eliminate any optical misalignment or other optical effects potentially influencing the calibration.

The data analysis was performed off-line using a spreadsheet to reduce the raw data. The spreadsheet was used to transform the filter signals to either emissivity values or temperature readings.

Glass samples were tested to determine if significant differences in emissivity resulted from compositional variations. These tests were conducted under quasi-isothermal conditions where minor gradients within the melt insignificantly influence the color temperature signatures. Data was analyzed off-line using the methods discussed in the earlier Phase I report. The emissivity of each sample of Gallo glass was compared according to the respective glass type. The 1990 and 1991 samples of Gallo green and flint were compared with each other.

Since the on-line calibrator was not shown to be absolutely reliable, the actual emissivity of the glass samples could not be determined with any degree of certainty. Therefore the glass samples were compared by adjusting the emissivity value for the ' 90 ' samples so the resulting calculated temperature corresponded to the measured reference triplex temperatures, this sample is the baseline. The same emissivity values were then used to estimate temperature of the 1991 samples. The data is shown for Gallo flint in Figures 4-1 through 4-4 and for Gallo green in Figures 4-5 through 4-8. The figures plot the TAS measurement temperature from the spreadsheet against the reference thermocouple reading at the glass surface. If the emissivity of the glass remained unchanged or the same over the two tests the two lines plotted should correspond 


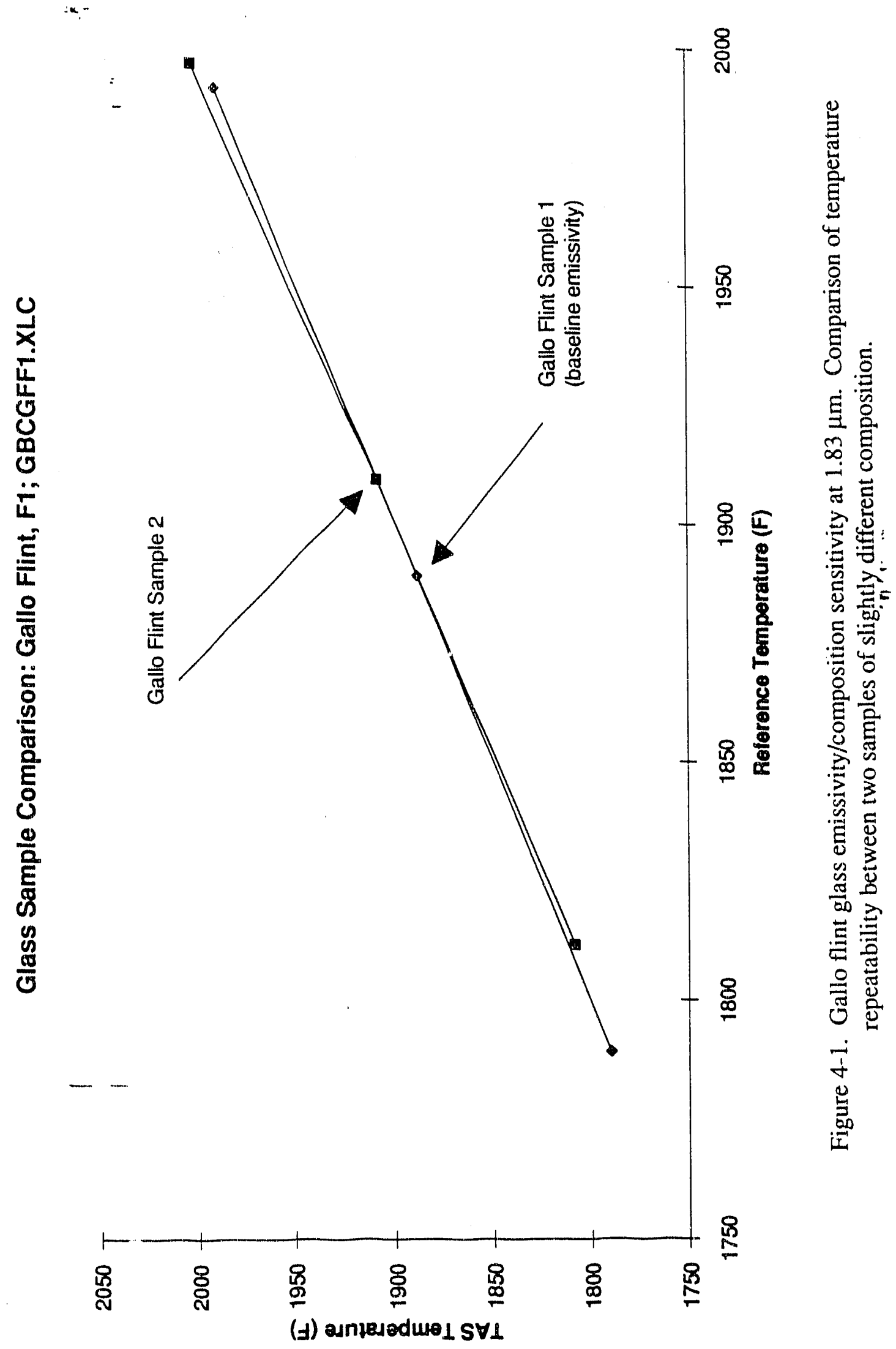




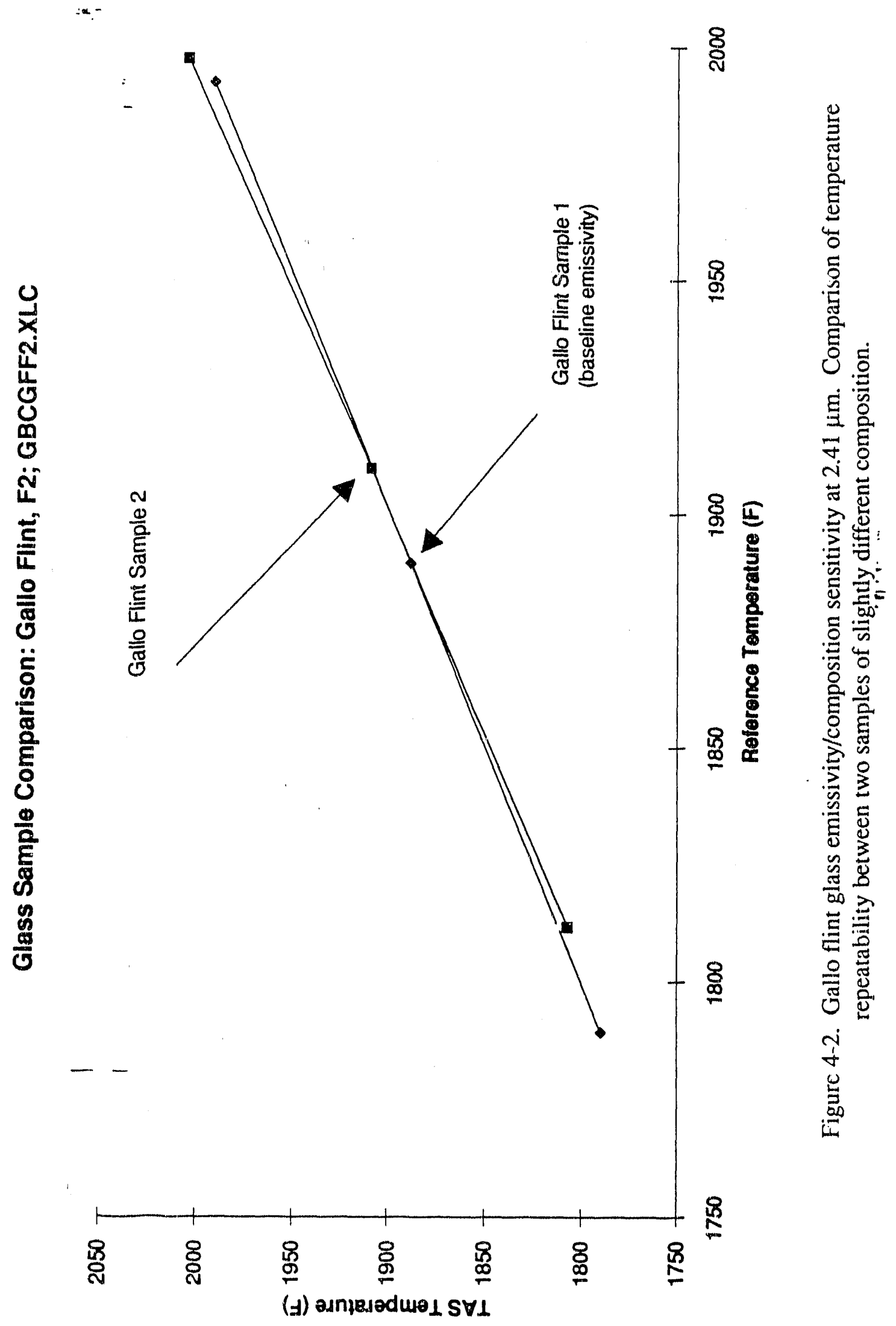




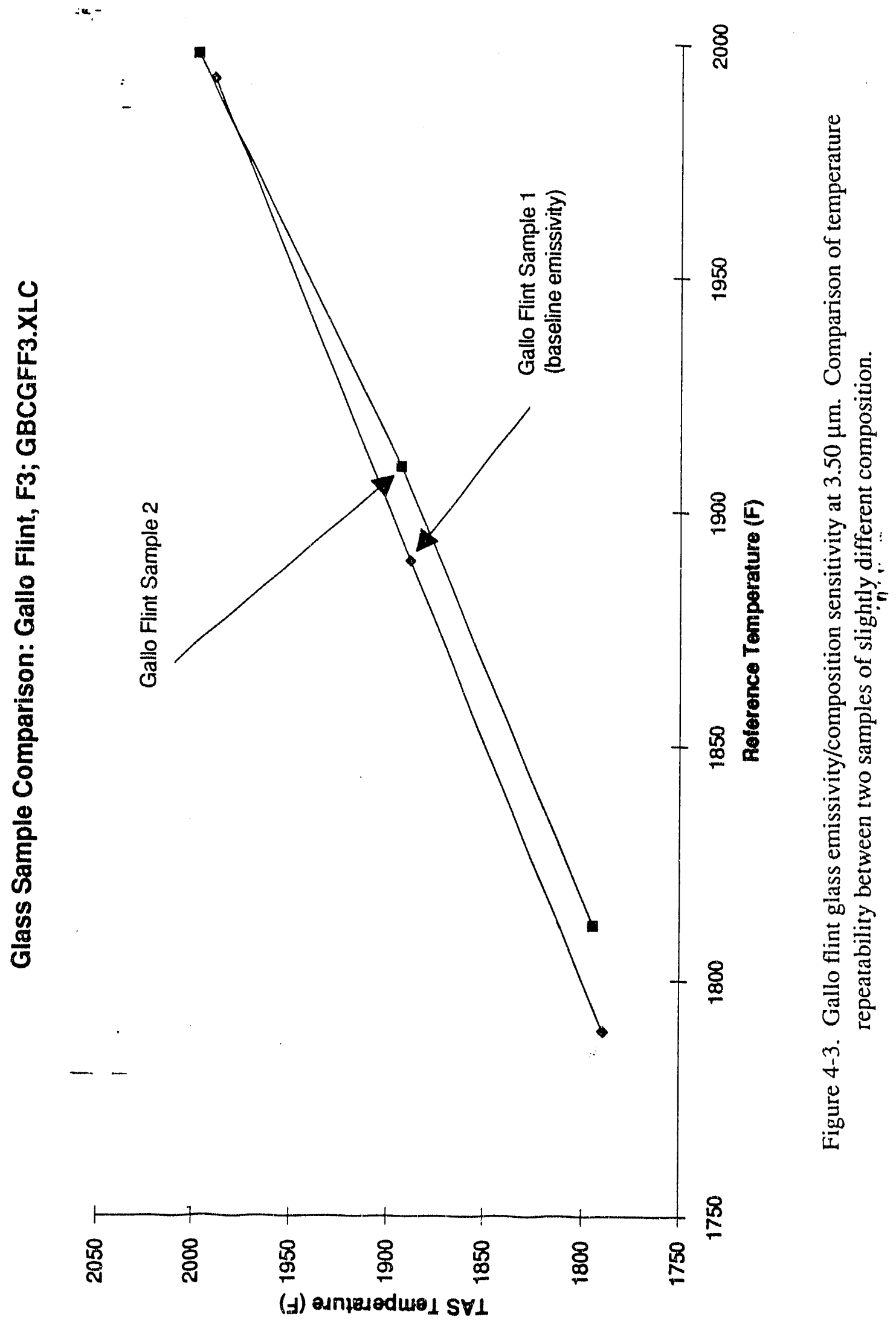




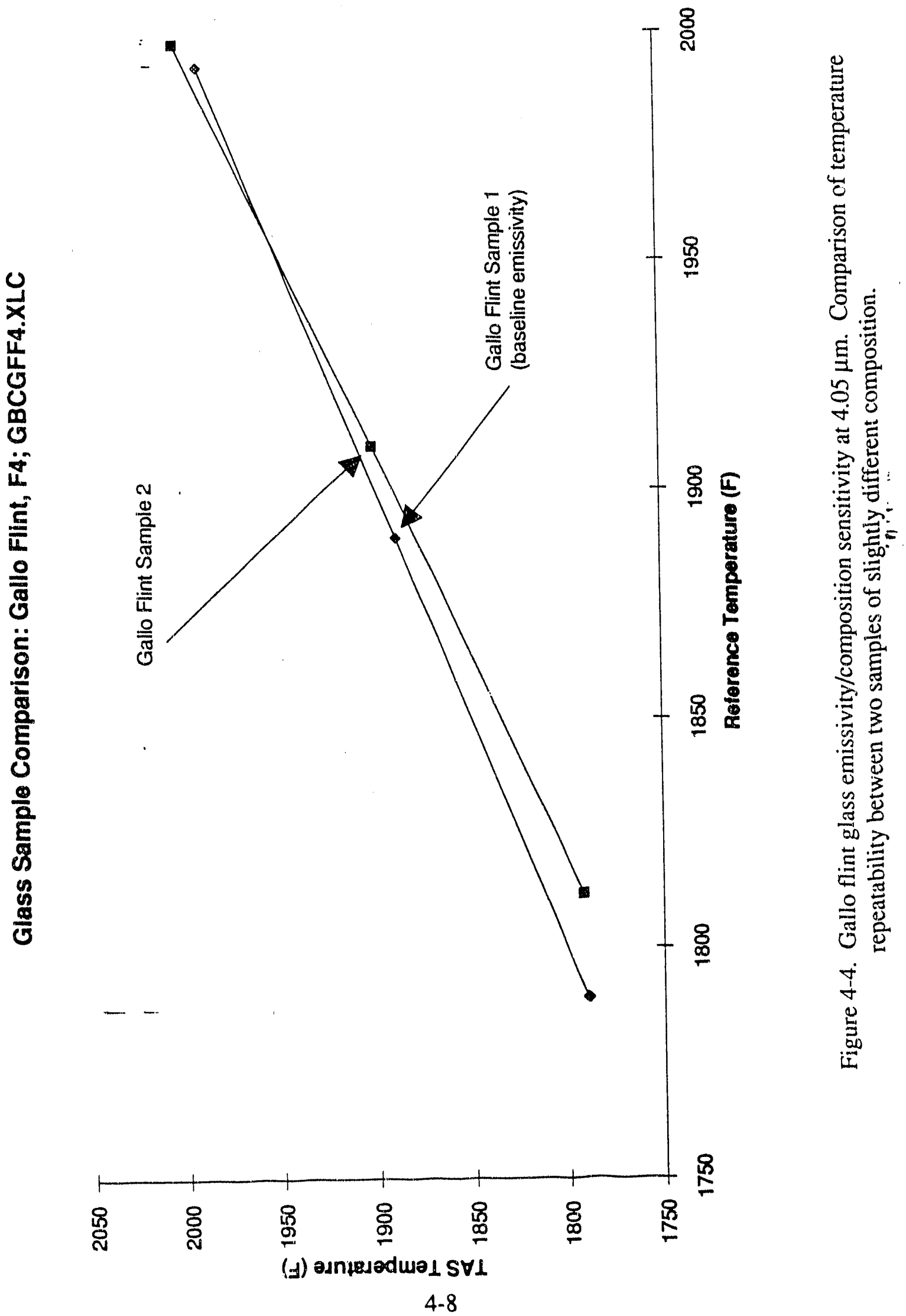




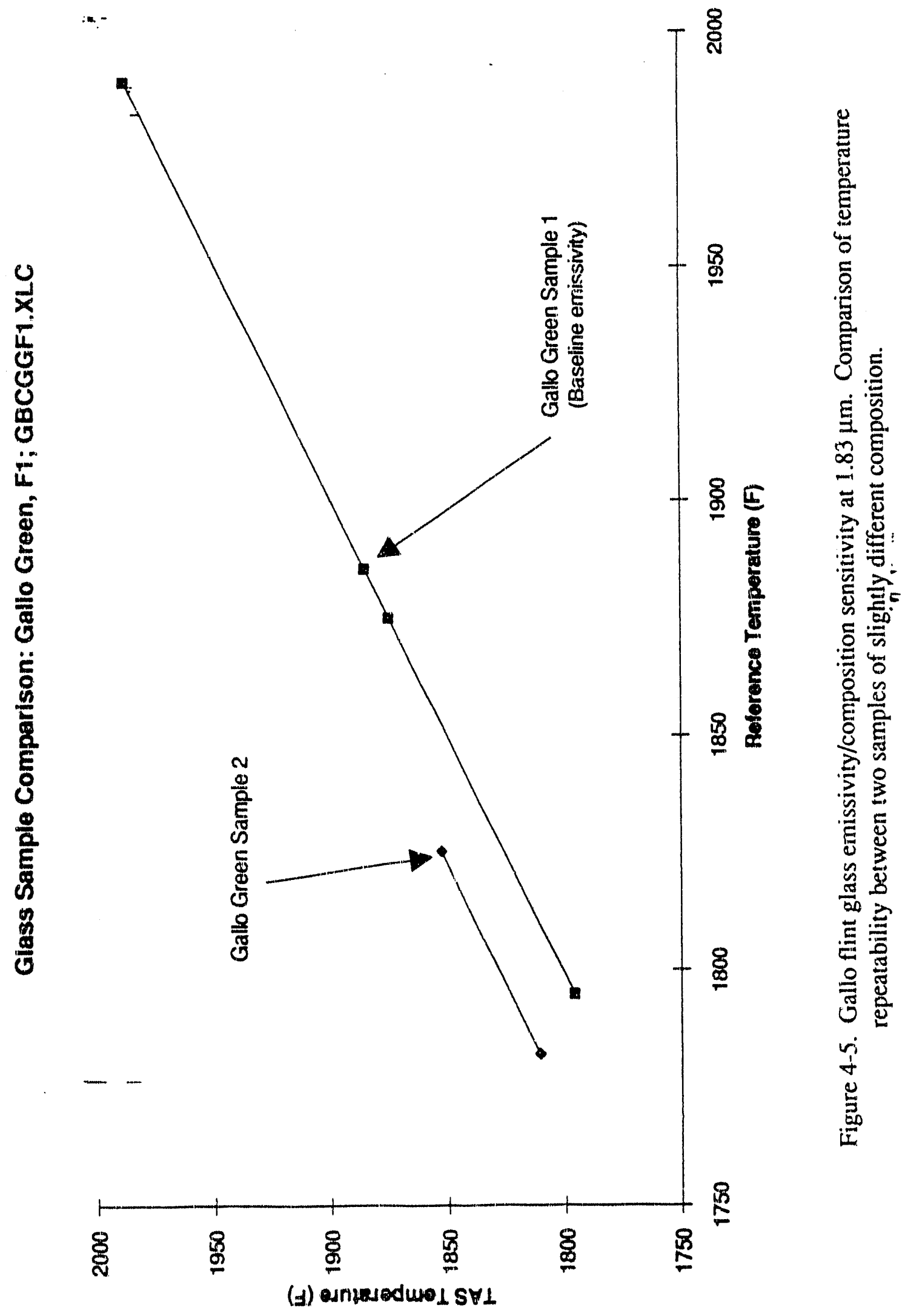




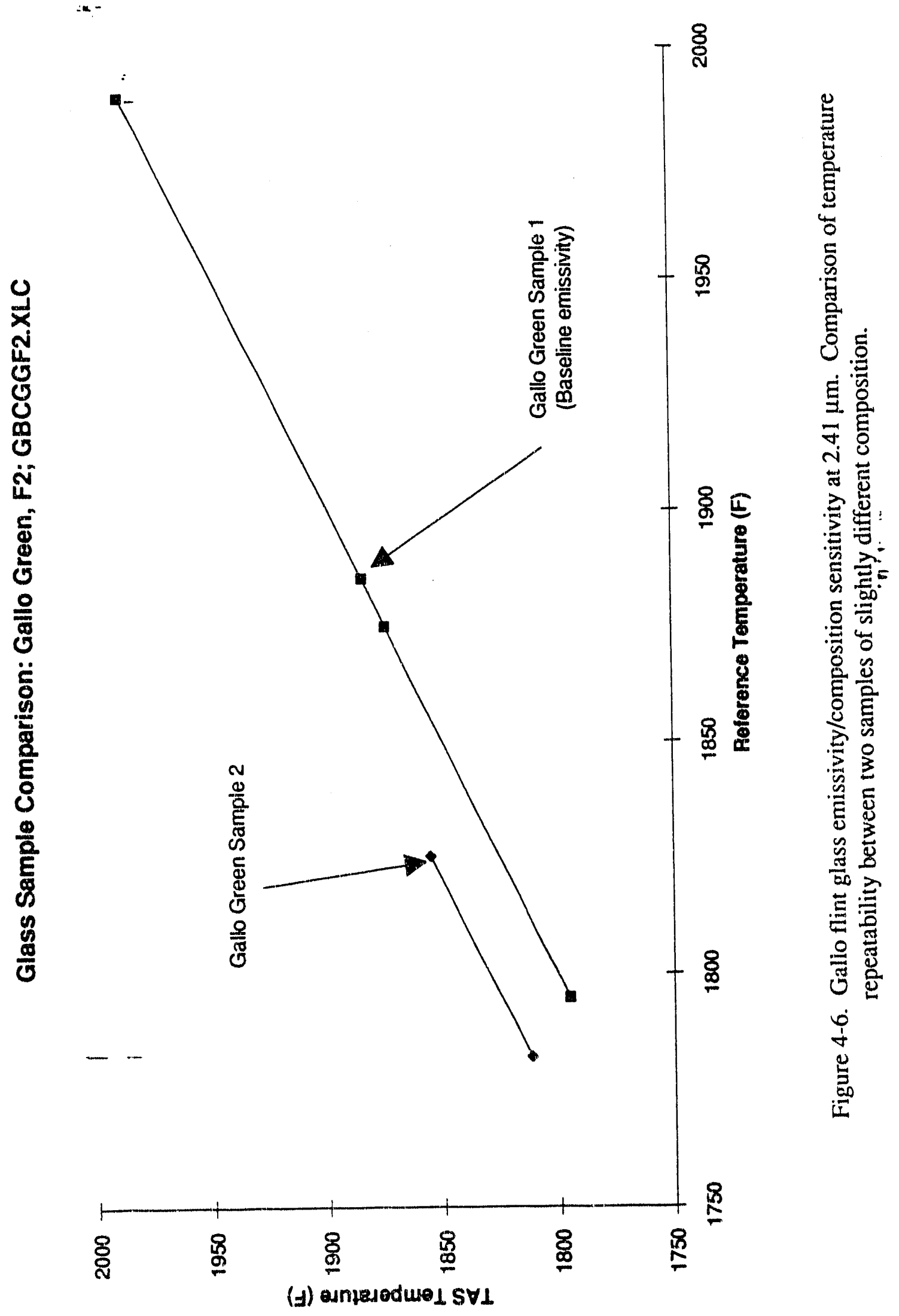

4- 10 


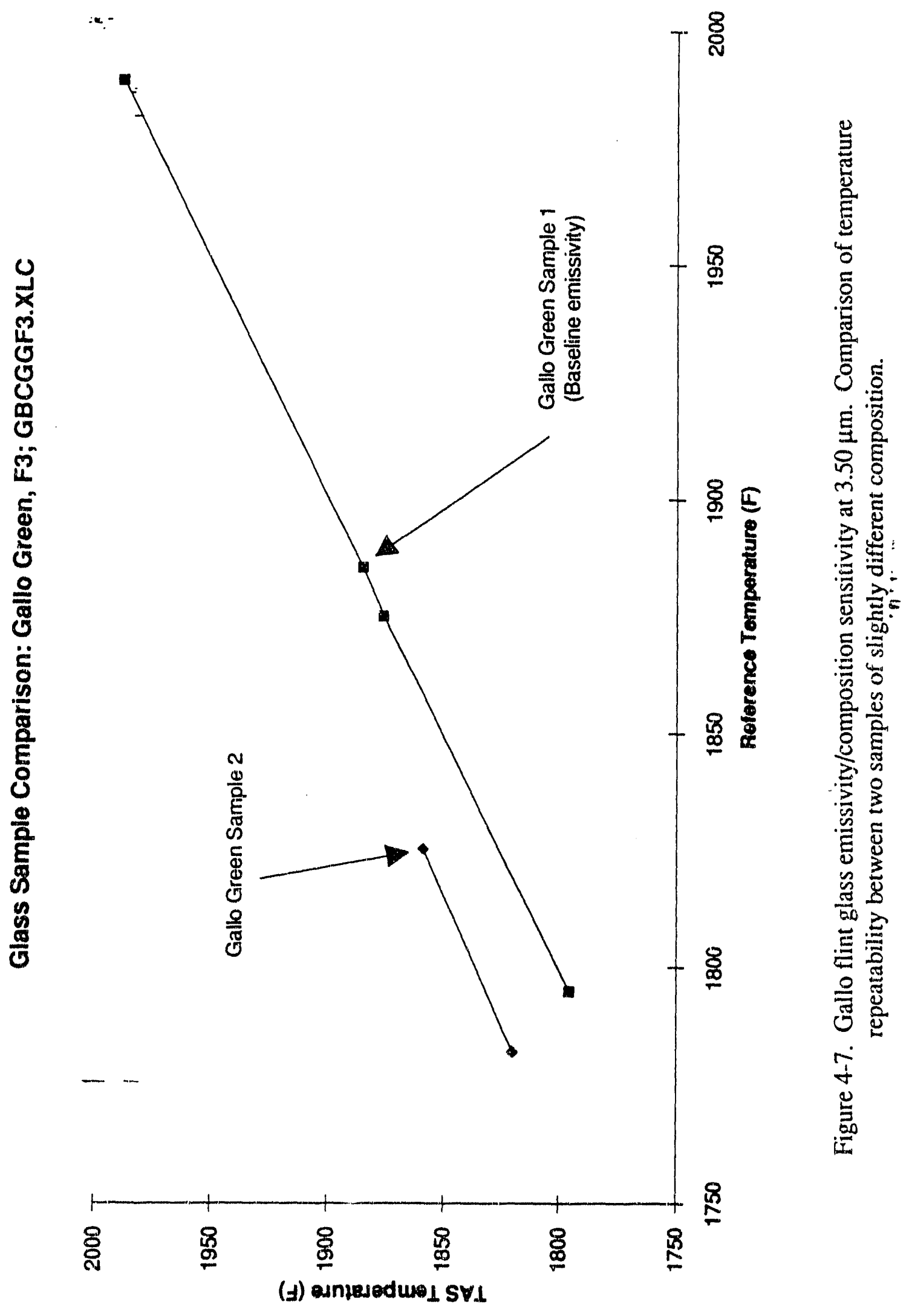




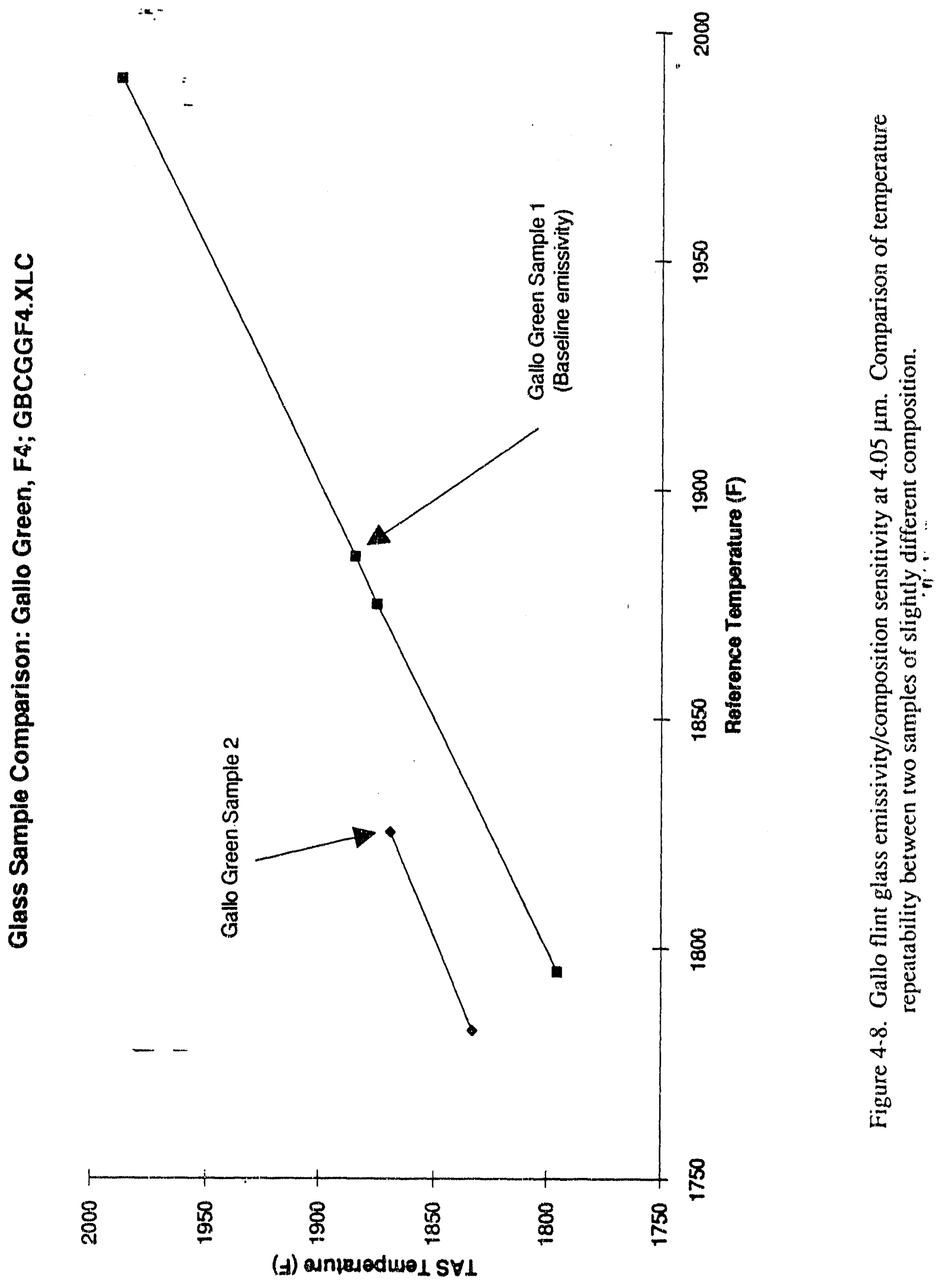


exactly. The data points plotted were selected at points where the glass batch melts were in a relatively stable thermal state, as opposed to being in transition.

The data on the Gallo flint glass samples compare best at the F1 and F2 (1.8 and $2.4 \mu \mathrm{m})$ wavelengths with the differences being the greatest at the higher temperature being $8^{\circ}$ and $9^{\circ} \mathrm{F}(4.4$ and $5^{\circ} \mathrm{C}$ ), respectively. The differences at F3 and F4 (3.0 and $\left.4.0 \mu \mathrm{m}\right)$ were considerably higher, $17^{\circ}$ and $20^{\circ} \mathrm{F}\left(9.4\right.$ and $\left.11^{\circ} \mathrm{C}\right)$ respectively.

These differences could result from any one of the following effects; singularly or in combination:

- reference thermocouple and analyzer errors as previously discussed.

- differences in glass absorption at different wavelengths due to impurities.

- $\quad$ other process variability as discussed below.

The discrepancies are believed to be more strongly linked to differences in surface effects thar compositional variations. The integrity of the surface of each glass sample was uniquely affected by debris and bubbles on the surface. For the majority of the tests, debris was not a problem; however in the case of the Gallo flint sample \#2 (1991) a small piece of refractory about $50 \mathrm{~mm}^{2}$ in area was found on the surface in the center of the crucible. The effect of this debris is unknown nor is it known for how long it was present since it was identified at the end of the test.

The effect of the bubbles on the surface is strongly believed to be influencing the emissivity measurements. The viscosity of the glass at the temperature range tested does not allow degassing of the glass (fining) at a rate significant to render a bubble-free sample within the testing time period. Degassing is an increasing function of temperature-time and thus, is changing in the course of the test runs. The result is a surface that is not flat or homogeneous but is dynamically changing.

The apparent differences between sample comparisons is coincident with the distinct differences in surface characteristics observed beiween the batch melts. The surface attributes of each sample is qualitatively described below: 


\section{$\therefore$ - Glass Batch Meit Qualitative Assessment}

Galle flint sample \#1 (1990): Tested under ambient furnace quasi-isothermal conditions. This batch was filled with ädditional glass to achieve the required melt depth for the second firing. It was tested on the second firing only. The surfice of the melt observed after the test sequence appeared typical of Gallo flint samples. This melt had heavy bubble inclusions on the surface. The estimated mean bubble diameter on the surface was $1.3 \mathrm{~mm}$. Macro bubble density near the surface $(5 \mathrm{~mm})$ was estimated at $1 / \mathrm{mm}^{3}$. Micro bubble density could not be estimated. This sample was cut in sections at the end of the test program. The maximum temperature subjected to this batch was $2040^{\circ} \mathrm{F}\left(1115^{\circ} \mathrm{C}\right)$.

Gallo flint sample \#2 (1991): Tested under induced gradient and ambient furnace quasi-isothermal conditions. This batch was filled with additional glass to achieve the required melt depth for the second firing. It was tested on the second firing only. After the first firing a piece of mullite refractory from one of the furnace roof plugs was observed in the melt. This piece was expected to sink to the bottom in the second firing after filling the crucible with more glass. This sample was run through the same temperature range as sample \#1 and had the same surface characteristics: The exception is the mullite chip which floated to the surface of the melt and was found in the direct center of the melt surface in the approximate position of the sensor viewing spot. The maximum temperature subjected to this batch was $2040^{\circ} \mathrm{F}\left(115^{\circ} \mathrm{C}\right)$.

Gallo green sample \#1 (1990); Tested under ambient furnace quasi-isothermal conditions. This batch was filled with additional glass to achieve the required melt depth for the second firing. It was tested on the second firing only. The surface of the melt observed at the end of the test sequence appeared typical of previous Gallo green batch melts. The surface had a very smooth glass like macro bubble free appearance. A piece chipped out of the melt was sketched in Figure 4Q9. The micro bubble fields were apparent in the chip and were estimated to have an average density of 3-5 bubbles/. $\mathrm{mm}^{3}$. The average diameter was estimated to be in the range of 50-100 $\mu \mathrm{m}$. The maximum temperature subjected to this batch was $2040^{\circ} \mathrm{F}\left(1115^{\circ} \mathrm{C}\right)$.

Gallo green sample \#2 (1991); Tested under induced gradient conditions. This batch was filled with additional glass to achieve the required melt depth for the second firing. It was tested on the second firing only. Due to an oversight in the test sequence, the maximum temperature subjected to this sample was $1840^{\circ} \mathrm{F}\left(1004^{\circ} \mathrm{C}\right)$. The surface of the melt observed at the end of the test sequence was distinctly different than any other batch melt. The surface had a matted texture which was not smooth. There were no macro bubbles on the surface as typical with the flint, and 


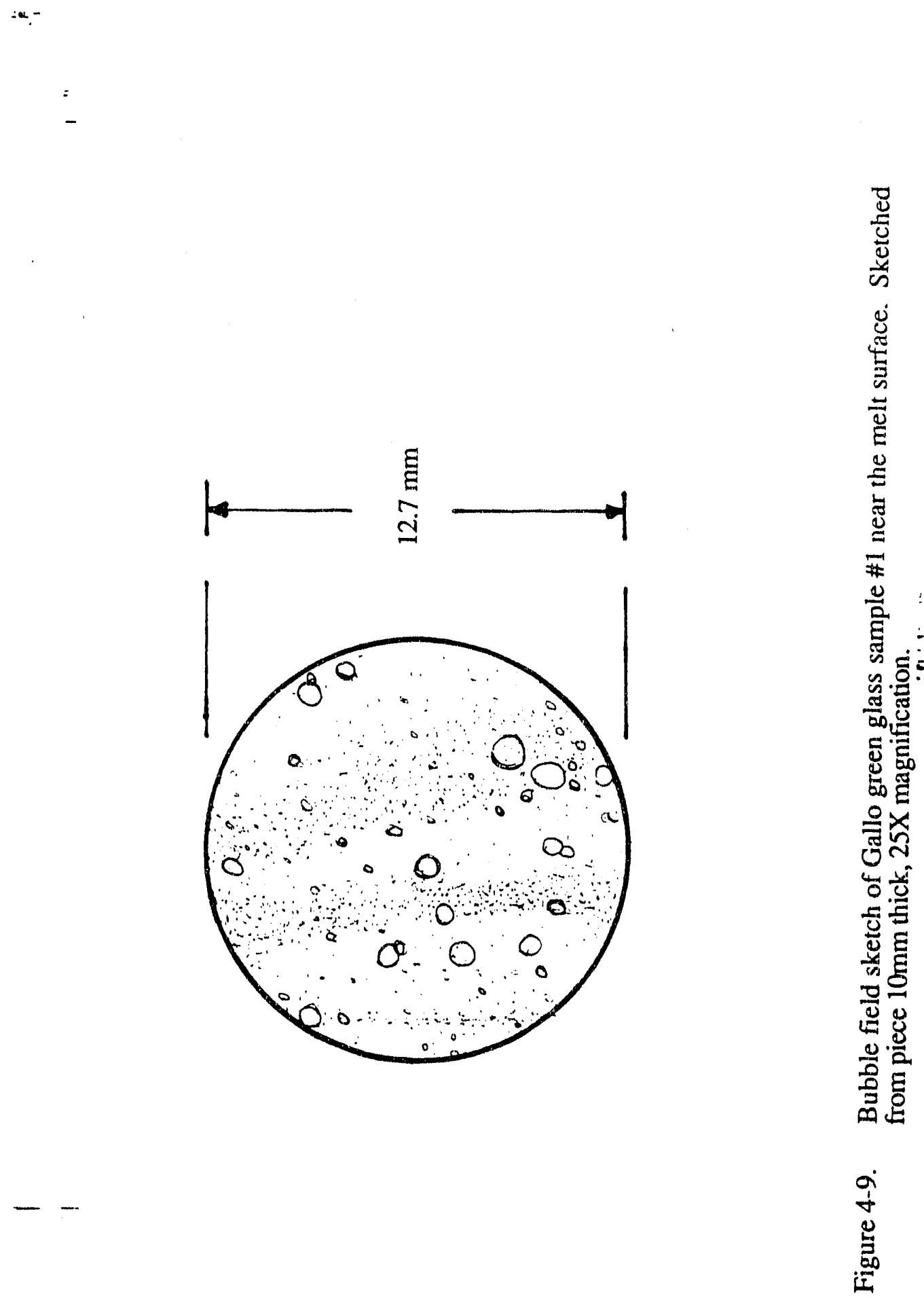


the micro bubbles could not be observed within the melt due to the surface roughness. It is believed the surface was in this state because an adequate temperature had not been reached to completely melt the added glass in the crucible.

The above descriptions qualitatively indicate that distinct differences in surface characteristics existed between batch melts of the same glass type. The green glass also indicated a dynamic change in surface flatness as the melt changes temperature. In the case of the flint glass, the macro bubbles probably were more raised in height and spherical in shape at the furnace temperatures relative to the observed flattened state at room temperature. It is speculated that as the melt cooled the gases in the bubbles contracted and the thin glass film encapsulating the top surface of the bubbles collapsed creating a smoother surface on the solid melt.

One of the major assumptions made in the theoretical development of the glass radiance and depth measurement model was that the glass is homogeneous and the surface is smooth and free of inclusions or debris. Inspection of the glass samples after each test showed in every case this. criteria had not been met. The green glass came very close but contained a large number of microbubbles. A sketch, Figure 4-9, of a $10 \mathrm{~mm}$ section of green glass near the surface shows bubble relative size and location. It is obvious the micro-bubble fields are significant and could heavily influence the internal transmission of radiation through the glass.

Non-isothermal testing was performed with each of the glass types by inducing a thermal gradient in the sample and analyzing the data at each wavelength. Since the previous work; a new $1.83 \mu \mathrm{m}$ interference filter replaced the $2.59 \mu \mathrm{m}$ filter used earlier 1 to improve depth resolution. The filters used throughout this test series are wavelength centered at 1.83, 2.41, 3.50, and 4.05 microns. The use of the $1.83 \mu \mathrm{m}$ filter should allow deeper measurement with flint glass. The optical depth of flint glass at this wavelength is nearly 3 inches.

As stated earlier one sample of each glass type was tested under an induced gradient. These tests were analyzed off-line using the spreadsheet to determine the temperature measurement capabilities of the improved TAS. The ability to measure temperature at depth in the glass relies on the ability to accurately measure differences between color temperature at the four wavelengths. In consequence the emissive properties the glass must be well understood in order to accurately measure temperature of the glass consistently. The surface imperfections discussed earlier prohibited developing emissivity data from the isothermal tests with which to characterize the glass color temperature measurements during the gradient test. 
The gradient test data did show close trending of the TAS temperatures at all filter wavelengths relative to the surface temperature reference. The trending information is valuable because the physical characteristics of the depth measurement should be apparent when measuring the transition from a gradient state to an isothermal state. If the TAS output is calibrated to indicate the surface temperature of the glass after an induced gradient has dissipated then the data taken during the gradient should indicate variations in the color temperatures in accordance to the absorption coefficients at the respective wavelengths, i.e. in a negative gradient state the longer wavelengths will show a color temperature at or just below the surface temperature and the shorter wavelengths will give a color temperature considerably lower than the surface temperature reference.

The potential for interference resulting from the presence of bubbles in the glass melt was first considered in the latter part of the earlier Phase I testing. At that time the bubble inclusions were noticed to be associated only with the flint glasses. Green glass appeared to be bubble free under the operating conditions of those tests. The primary differences between the earlier tests and these tests is the temperature applied to the samples and the period over which the samples were: fired. The present tests were run at no more than $2040^{\circ} \mathrm{F}\left(1115^{\circ} \mathrm{C}\right)$ for no more than two: consecutive days due to degradation of the furnace and scheduling/budget limitations. The earlier tests permitted firing the crucibles at temperatures up to $2250^{\circ} \mathrm{F}$ and most samples were run for a week or more at $2000^{\circ} \mathrm{F}\left(1093^{\circ} \mathrm{C}\right)$.

The higher melting temperatures and particularly the longer firing periods contributed to conditioning the green glass samples well enough to allow the depth measurement made in the earlier tests. The combination of the bubble formation, the drift and noise problems found in that earlier test phase contributed to the inability to deconvolute the flint glass data. As a result of the ambiguity of the previous results and the perceived signal stability problems, the true interference potential of bubble inclusions in the glass samples was not conceivable. The bubbles were noticed in the glass samples but the data did not indicate any direct relationship between the bubble presence and ambiguous tempcrature measurements in the earlier test phase.

Analysis of all gradient data showed very little difference in the temperature readings between the four filter wavelengths. The implication is that radiation at depth in the glass has been impaired. This impairment is attributable to the presence of bubbles within the batch melts tested and is discussed in the following section. 


\subsection{Test Analysis and Interpretation}

Electromagnetic transmission through the glass media is affected by changes in absorption caused by chemical composition (molecular) or phase interfaces (bubbles and seeds).

Bubble size will strongly influence the mechanisms of interference/attenuation. The bubbles will interact with the infrared radiation via both scattering and reflection. The scattering effect is caused by diffraction of light as it passes through a particle. This effect is strongest when the particle sizes are of the same order as the wavelength of light. In the case of scattering, the bubbles in the glass can be assumed to behave like particles.

Reflection and refraction both occur when electromagnetic radiation is incident at a phase interface such as the air/gas-glass boundary of a bubble. Reflection and refraction depend on the angle of incidence with the interface and the ratio of the indices of refraction between the two media. Both the intensity and direction of electromagnetic radiation is affected by the complimentary, properties of reflection and refraction.

Visual observation suggests that a significant percentage of the bubbles in the glass were of a size considerably larger than the wavelengths of light used. For the green glass samples, bubble sizes are estimated to be less than $500 \mu \mathrm{m}$ and typically of the order of 50-100 $\mu \mathrm{m}$. This is large in comparison to the infrared wavelengths of $1.8-4.0 \mu \mathrm{m}$.

Bubble interference analysis requires a complex solution to describe the behavior of infrared radiation within the test glass melts. The general solution for large particle scattering is described by Mei scattering. Mei scattering is insignificant for particles of diameter less than $1 / 10$ th the wavelength of light. Scattering theory ${ }_{2}$ estimates the attenuation of the light beam intensity through a distance $x$ assuming a media with isotropic scattering centers:

$$
-\quad I=I_{0} e^{-(K+\tau) x}
$$

Where $\kappa$ is the absorption coefficient and $\tau$ is the turbidity coefficient. The turbidity coefficient describes the total light power scattered through all angles from a volume with $N$ scatterers of radius $R$. Mei theory treats scattering as an electromagnetic-wave boundary-value problem. Plane waves incident at the appropriate boundary conditions of the bubble surface are scattered according to the 
turbidity parameter $\tau$. The simplified result describes the contribution to the turbidity coefficient as a function of $N$ spheres (bubbles) of radius $R$ in a unit volume, which is

$$
\tau=N \pi R^{2} f(y)
$$

where,

$$
\begin{aligned}
y & =\frac{2 \pi R}{\lambda^{\prime}} \\
\lambda^{\prime} & =\frac{n}{\lambda}
\end{aligned}
$$

The index of refraction of the glass media is denoted by $n$ and $\lambda$ is the wavelength of light being scattered. The function $f(y)$ is very complicated but has the following limiting forms:

$\begin{array}{ll}\text { Proportional to } y^{4} & \text { for } y<1 \\ \text { Proportional to } y^{2} & \text { for } y \sim 1 \\ \text { Approaches the value 2 } & \text { for } y>1\end{array}$

For the estimated bubble size and density combinations, $y$ was typically 100 or greater, indicating the latter limit applies.

The impact of Mei scattering on the ability to perform depth transmission measurements was evaluated using the equations above. The optical depth penetrated assuming bubble number density (bubbles in a unit volume) for several bubble sizes, is estimated for green glass at $2.4 \mu \mathrm{m}$ and flint glass at $1.8 \mu \mathrm{m}$ respectively, Figures 4-10 and 4-11. These figures demonstrate the strong influence of bubbles on the ability to measure temperature at depth. Clearly the number density of large bubbles is expected to be much less than that for smaller bubbles. A detailed analysis of the bubble size distribution and number density was not performed; however, it is estimated the average value for $N$ is the range of $1-5$ bubbles $/ \mathrm{mm}^{3}$ for the glass samples tested. This estimate was made by inspection of sectioned test glass samples in regions near the surface. It should be noted that for the Gallo flint glass the bubble density on the surface exceeded the values estimated above. This glass had a bubble foam on the surface in most cases. 
Given the above analysis of bubble interferences induced by Mei scattering, it is clear that temperature can not be measured to any appreciable depth into the glass. These results show further gradient and surface temperature tests will be meaningless unless the glass samples are first degassed to remove the adverse effects of macro and micro-bubbles. 


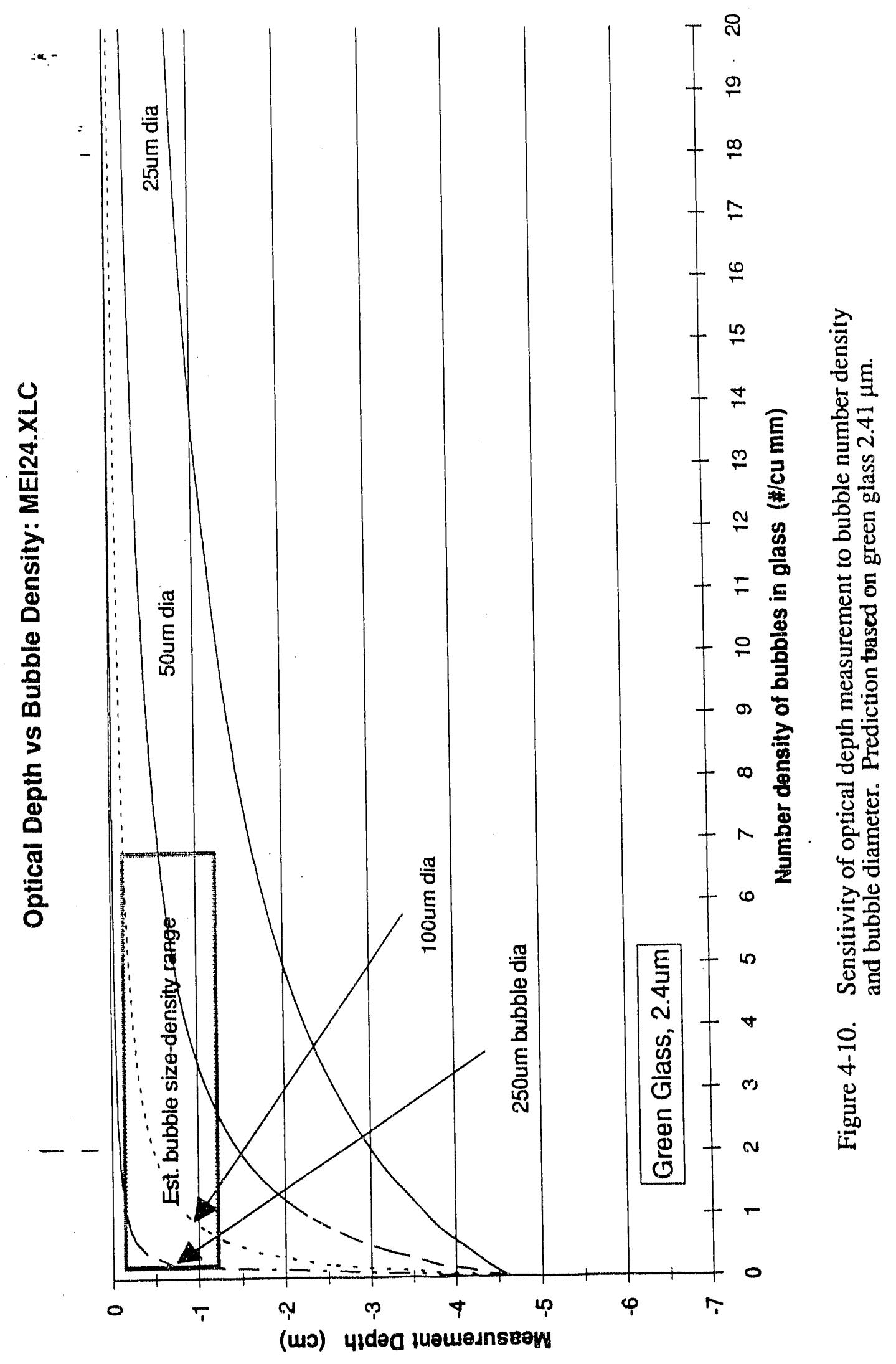




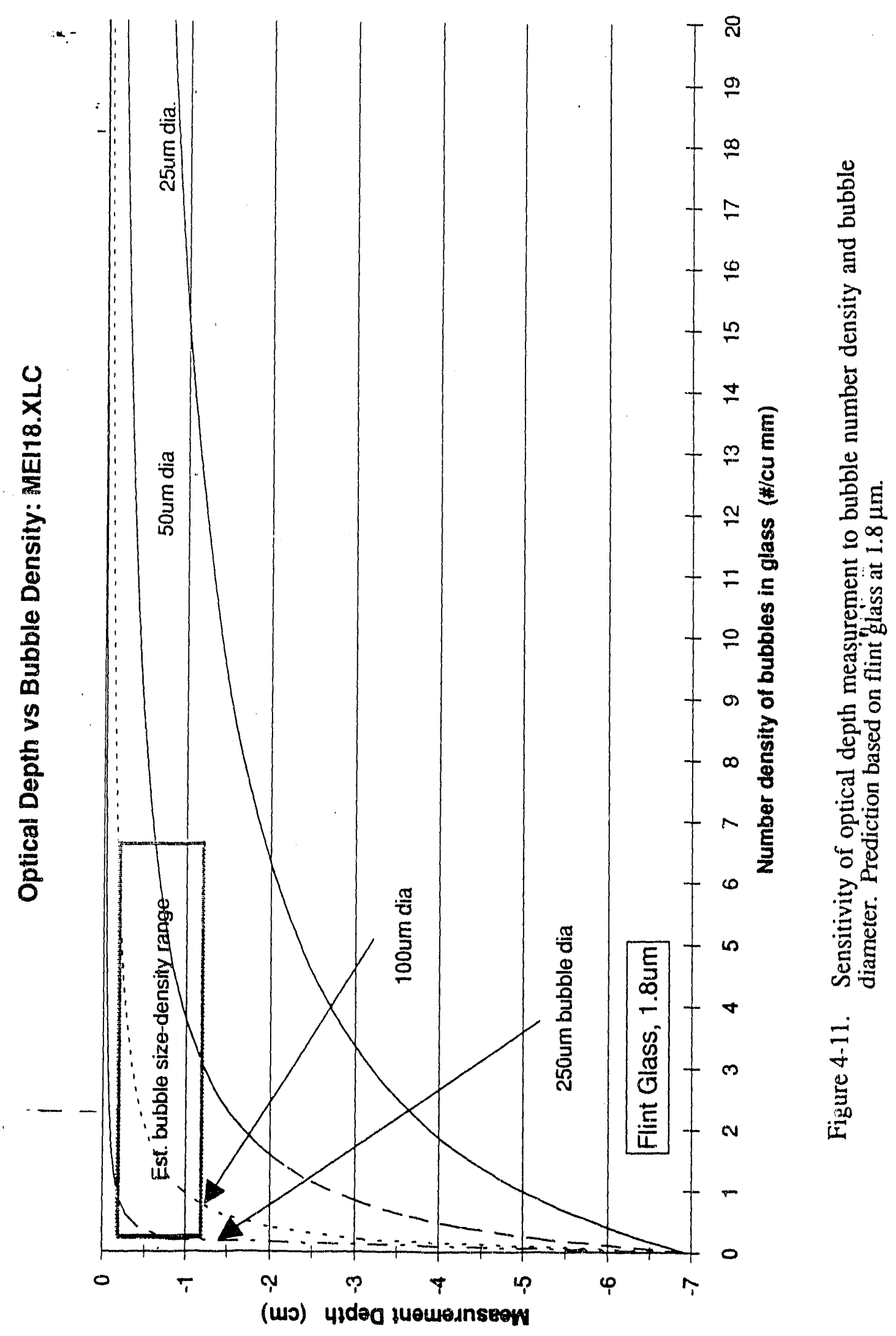




\section{$5.1 \quad$ Conclusions}

Based upon the above discussion the following are concluded:

1. Analyzer long term drift and short term noise improvements have resulted in inherent accuracies of about $+1 / 2^{\circ} \mathrm{C}$, about equivalent to the black body calibration source.

2. Four different concepts of heating elements were evaluated for use in an in-situ secondary calibration source. The use of a SiN igniter element shows some promise, but requires considerable development.

3. The black body reference is the soutce of some of the apparent diumal analyzer drift due to ambient temperature changes.

4. The analyzer has strong ambient temperature sensitivities, specifically the detector and optical bench, which can be substantially mitigated with good internal temperature control (enclosure and detector).

5. Pilot furnace tesis using poorly degassed glasses resulted in data which makes conclusions regarding the effects of glass composition and gradient resolution impossible.

6. The impact of bubble inclusions in the glass melt can yield a significant degradation in depth measurement capability as a result of Mei scattering from the bubbles. The degree of degradation depends on bubble size and number density.

A scheme for calibrating the analyzer without using a black body reference was successfully applied on the pilot tests and suggests an alternate approach to an in-sensor secondary calibrator: 
- Core a second hole (1"dia) next to an existing glass sensor.

- Periodically (field test to determine) insert a triplex thermocouple and initiate a sensor ealibration mode (all automatic under analyzer control).

This approach returns the concept to a simple passive sensor design and a calibration relative to an industrial standard. Some additional instrument technician labor is incurred, but it should be modest if system stability is sufficient to require only monthly calibrations.

\section{2}

\section{Recommendations}

With this curnulative background and experience two approaches to continuing the project were considered:

1. Implement the Phase II, Industrial Testing and Verification, at Gallo initially with two sensors and the current prototype signal processing unit.

2. Procure a thermally compatible crucible, melt and degas the glass in a contracted, high temperature furnace at $2600^{\circ} \mathrm{F}\left(1400^{\circ} \mathrm{C}\right)$, then use the preconditioned melt in the pilot furnace.

These options are briefly described below:

\section{Phase II Implementation}

Sufficient development and proof of principle work has been completed to execute a multiple sensor installation at Gallo with low risk. The sensors would be placed adjacent to existing triplex thermocouples and the pilot scale experiment would be substantially duplicated. This approach avoids the complexity of attempting a process simulation and should provide a clear go-no go decisiontregarding the integration with the forehearth control system. The combined analyzer data base of:

- The earlier pilot furnace experiments, methods evaluation and concept development.

- The black body stability tests with the newly improved sensor design. 
- Thecurrent pilot furnace surface temperature data.

suggests this to be low risk, low cost approach producing an unambiguous result.

It may be feasible to degas several crucible melts in a higher temperature furnace $\left(\sim 2600^{\circ} \mathrm{F}\right)$ and then reheat them in EER's pilot furnace.

The primary concern is that glass coefficients of expansion are not well matched to high temperature ceramics $\left(\mathrm{Al}_{2} \mathrm{O}_{3}, \mathrm{MgO}\right.$, etc.). Thermal stress cycling weakens the crucible and results in a short campaign life of usually 2 to 3 thermal cycles.

These are also very expensive $(\$ 800)$ vis-a-vis the $\mathrm{Zr}_{2} \mathrm{O}_{3}$ crucibles currently being used $(\$ 100)$. Assuming the compatibility problem is resolved, we're still faced with an imperfect process simulation since:

- there are significant axial gradients in the melt as evidenced by paired triplex: thermocouple measurements

- the furnace is no longer capable of design temperature operation

A full scale Phase II implementation is therefore recommended. The host site also concurs with this recommendation and is willing to proceed. 
6.0 REFERENCES

1. Gardner, M. J., J. Kramlich, R. Koppang, A. Candee; Development of a Process Controt Sensor for the Glass Industry, Phase I Report, DOE Report Number DOE/ID/12781-1. Energy and Environmental Research Corp. May 1991.

2. Condon,E.U. and Hugh Odishaw: "Handbook of Physics," 2nd ed., pp 6-125 to 6-129, McGraw-Hill Inc., 1967. 


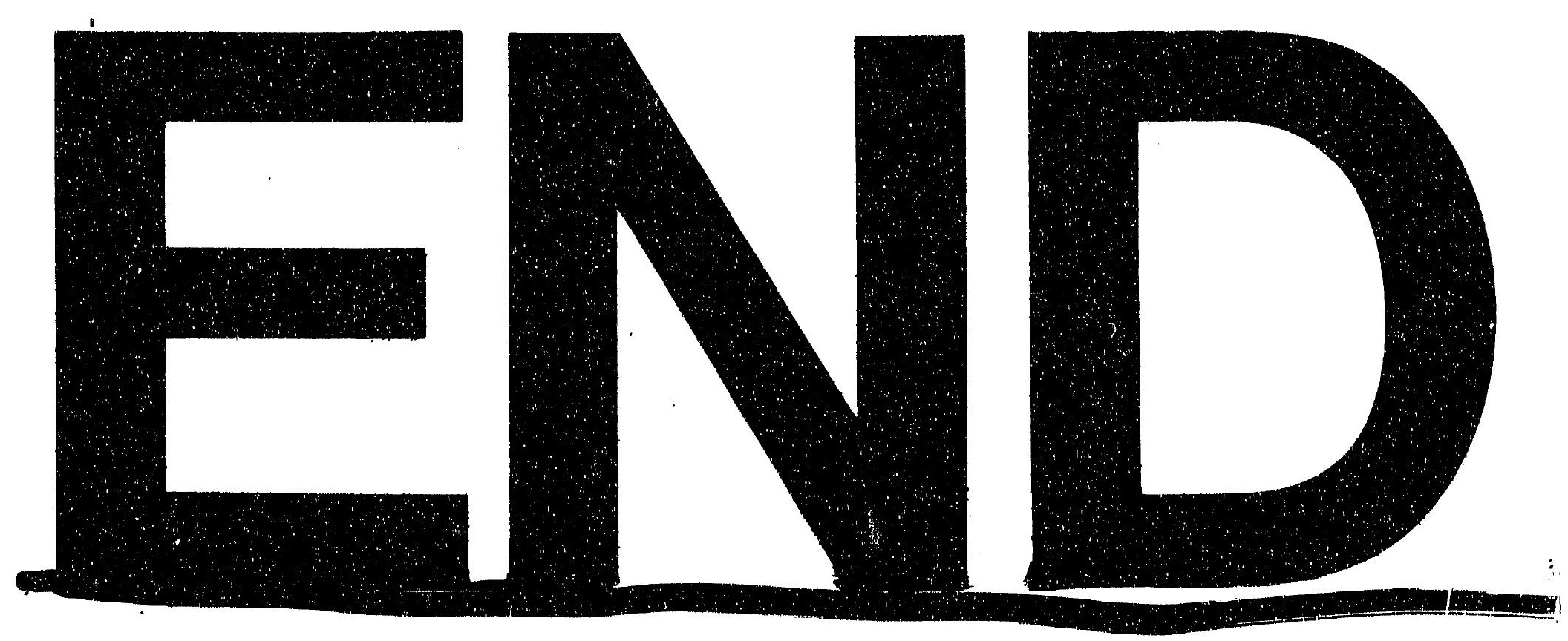

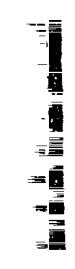
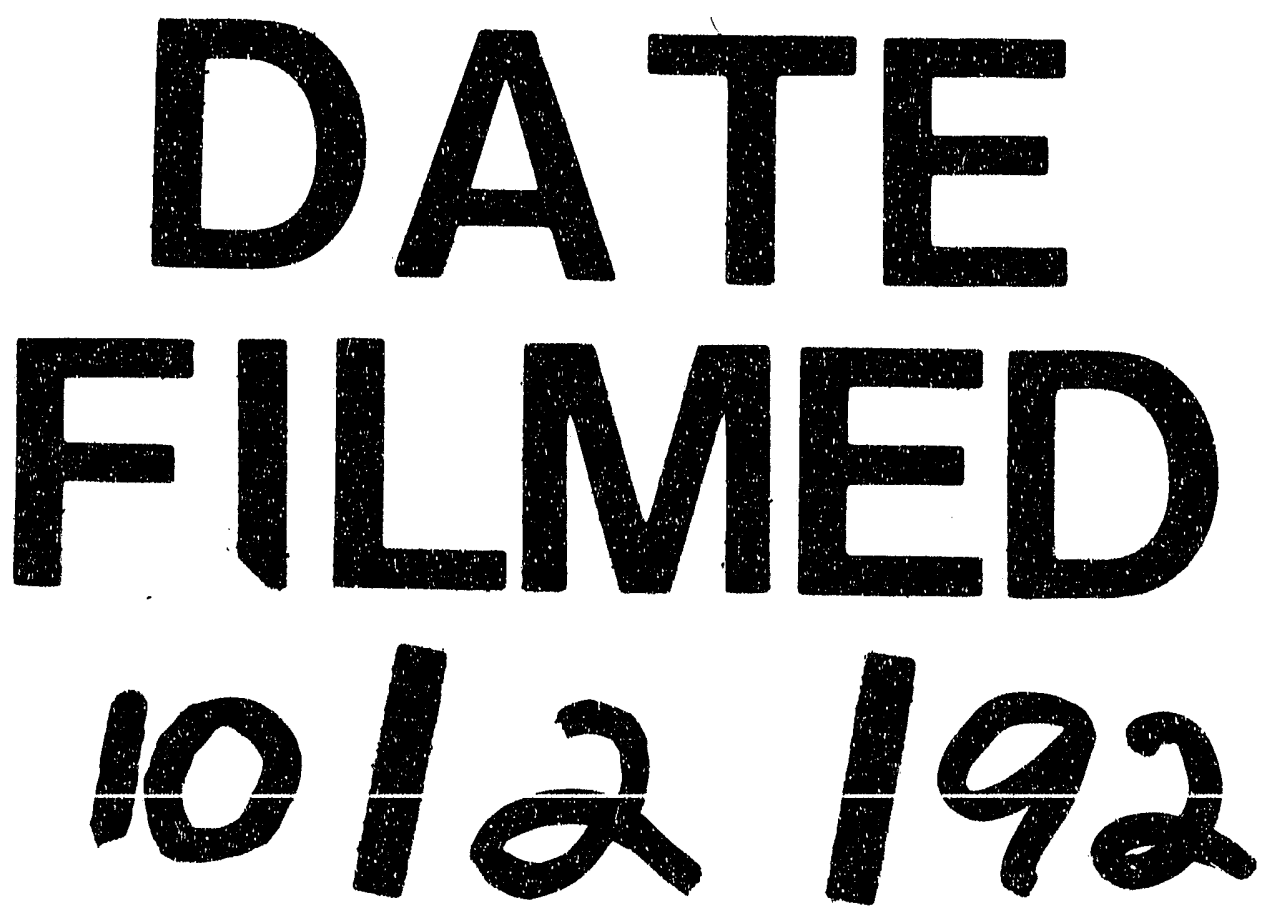


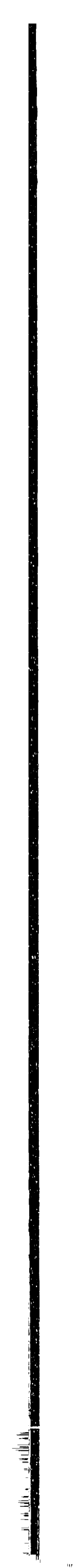

